WILENMANN, Javier. "El sistema de graduación de la pena del homicidio en el derecho chileno".

Polít. crim. Vol. 11, No 22 (Diciembre 2016), Art. 12, pp. 721-765.

[http://www.politicacriminal.cl/Vol_11/n_22/Vol11N22A12.pdf]

\title{
El sistema de graduación de la pena del homicidio en el derecho chileno
}

\section{The system for determining the penalty for homicide in Chilean law}

\author{
Javier Wilenmann von Bernath* \\ Dr. Iur. Albert-Ludwig Universität Freiburg \\ Profesor Facultad de Derecho Universidad Adolfo Ibáñez \\ javier.wilemann@uai.cl
}

\section{Resumen}

A partir de la identificación de una función institucional históricamente dominante en la regulación del asesinato $\mathrm{u}$ homicidio calificado - hacer procedente la aplicación de la pena de muerte o el presidio perpetuo - y de una reconstrucción de modelos históricos y comparados de realización de esta función, el artículo presenta una reconstrucción dogmática de las distintas formas de homicidio, y en particular del homicidio calificado, en el derecho chileno, así como del sistema de graduación de la pena que le subyace. El artículo muestra que el sistema chileno establece un sistema mixto de graduación de la pena, el que contiene en la regla de la premeditación un criterio general de graduación complementado por circunstancias especiales. Como el criterio genérico de graduación (la premeditación) solo puede ser correctamente comprendido desentendiéndose de la construcción del homicidio simple como tipo básico, una interpretación adecuada lleva a invertir parte de las categorías heredadas por la doctrina. El artículo finaliza mostrando la completa concordancia entre esta interpretación y los marcos legales del artículo 391 del Código Penal y el modo en que deben construirse criterios de determinación de la pena a su respecto.

Palabras clave: Homicidio calificado, asesinato, premeditación, pena de muerte, presidio perpetuo.

\footnotetext{
* Profesor Facultad de Derecho Universidad Adolfo Ibáñez. Una primera versión de este artículo fue expuesta en las Jornadas Patagónicas de Derecho Penal realizadas en marzo de 2016 en Coyhaique. Le agradezco a la Fiscalía Regional de Coyhaique por la invitación a exponer en dicha ocasión, la que supuso el impulso inicial de esta investigación. Mis más profundos agradecimientos institucionales le corresponden, sin embargo, a la Alexander von Humboldt Stiftung: parte del artículo fue escrito en Alemania en mayo de 2016 en el curso de una estancia de investigación posibilitada por una beca otorgada por ésta. La investigación tuvo lugar en el Institut für Strafrecht und Rechtsphilosophie dirigido por el profesor Michael Pawlik en la Albert-Ludwigs Universität Freiburg y en la biblioteca del Max Planck Institut für ausländlische und vergleichende Strafrecht de la misma ciudad, por lo que agradezco la generosidad de estas instituciones. También debo agradecer a la profesora Annette Grünewald de la Humboldt-Universität zu Berlin por una conversación relativa al contenido de este artículo, y al profesor Pablo Sánchez Ostiz por la realización de valiosos comentarios a una primera versión del mismo. Por último, la investigación contó con la invaluable ayuda de Nicolás del Fierro y sobre todo con la colaboración de Juan Pablo Aristegui, a quienes van mis más sinceros agradecimientos.
} 
WILENMANN, Javier. "El sistema de graduación de la pena del homicidio en el derecho chileno".

\begin{abstract}
The article presents an interpretation of murder in Chilean law. It proceeds by identifying the institutional purpose of murder as a rule to distinguish homicides in which capital punishment (or life imprisonment) is applicable from those that it is not, as well as different comparative structural models in the fulfillment of this goal. The article shows that Chilean law follows the dominating comparative trend in establishing a mixed model, which recognizes both a general (premeditation) and special criteria to distinguish between both kinds of homicides (capital and non capital homicides). As the general criterion is only well understood if premeditated homicide is not constructed as special homicide but rather manslaughter is seen as a privileged intentional homicide, the article departs from the traditional systematic interpretation of murder in Chile.
\end{abstract}

Key words: Murder, manslaughter, premeditation, death penalty, life imprisonment.

\title{
Introducción
}

Es probable que existan pocos artículos del Código Penal chileno (en adelante "CP”) que sean tan familiares a un penalista (o, en general, a un abogado) chileno como el artículo 391 CP. Pese a esa familiaridad, es igualmente probable que su lectura produzca una impresión de heterogeneidad a causa de la enumeración de casos que lo caracteriza. El artículo 391 $\mathrm{CP}$ parece constituir así un caso paradigmático de aquello que peyorativamente tiende a denominarse "legislación casuística": se trataría de una disposición que enumera casos que parecen no tener relación entre sí, pero respecto a los cuales la legislación simplemente establecería la aplicación de una misma consecuencia jurídica, por lo que su tratamiento sistemático resultaría una empresa inadecuada. Esta representación ciertamente tiene verosimilitud: pocas disposiciones de la Parte Especial del CP contienen formas de enumeración de situaciones tan heterogéneas como el artículo 391 número 1 CP. Así, por ejemplo, el CP ciertamente contiene muchas reglas que califican al delito de lesión corporal, pero es posible reconocer al menos un criterio común que explica casi todos los casos, a saber, la intensidad del resultado de lesión. De hecho, es probable que el resultado de realizar un ejercicio mental de preguntarse "qué disposición conozco del CP que tenga una estructura similar al 391" sea "los artículos 11 y 12 CP”. Esta asimilación puede verse, tal vez, incentivada por el hecho de que el contenido de buena parte del artículo 391 número 1 se encuentra en los primeros numerales del artículo $12 \mathrm{CP}$ (alevosía, veneno, etc.) - tal vez el argumento sea, por ello, tramposo - pero es en cualquier caso llamativo que una disposición central de la Parte Especial tenga un parecido tan evidente con un listado de agravantes ${ }^{1}$.

\footnotetext{
${ }^{1}$ Por cierto: puede que sistemáticamente adecuado que el contenido de reglas generales de determinación de la pena (agravantes) y reglas de calificación típica sea similar; ello se justificaría en lo que uno puede denominar de modo grueso como coincidencia en los criterios de agravación del injusto. Así, sería natural (aunque ciertamente no necesario) que aquello que en general es considerado como agravante del injusto también lo sea respecto de clases de hecho particulares. La utilización de la técnica de la calificación se explicaría así solo por razones penológicas. Pero ese argumento solo hablaría contra la heterogeneidad de la forma de calificación típica si las agravantes generales estuvieran constituidas de un modo sistemáticamente limpio y no casuístico - no heterogéneo. Ese ciertamente no es el caso del artículo $12 \mathrm{CP}$.
} 
Polít. crim. Vol. 11, No 22 (Diciembre 2016), Art. 12, pp. 721-765.

[http://www.politicacriminal.cl/Vol_11/n_22/Vol11N22A12.pdf]

Esta sensación de heterogeneidad se opone, sin embargo, a una segunda característica que también tiende a ser atribuida al homicidio calificado: se trata de un conjunto de reglas que caracterizan a un hecho con una identidad cultural unitaria. Este no es el caso de otras formas de graduación de la pena en la Parte Especial. No tiene demasiado sentido afirmar que un hurto de una cosa cuyo valor excede las 40 Unidades Tributarias Mensuales (en adelante "UTM") es un hecho con una identidad cultural distinta al hurto de una cosa cuyo valor es inferior a 40 UTM pero superior a 4 UTM. Las reglas de graduación de la pena del hurto no parecen distinguir clases de actos, ya no hay nada especialmente distinto en el hurto de una $\mathrm{u}$ otra cosa dependiendo del valor, sino que se trata de reglas de pura graduación de la pena. En cambio, el homicidio calificado no parece constituir una regla referida exclusivamente a la graduación de la pena, sino que parece tratarse de reglas que instituyen una unidad con una identidad típica propia. En otros sistemas, ello se expresa por medio del uso de otras convenciones lingüísticas para designar al homicidio calificado: no es sólo un homicidio en el que concurre una circunstancia calificante, sino que es también otra cosa, a saber, un asesinato ${ }^{2}$, un Mord o un (first degree) murder. La concesión de una identidad autónoma llega al paroxismo en la jurisprudencia alemana y en la doctrina española: a partir de la asunción de su correspondencia con categorías culturales generales, se concluye a veces (incorrectamente) que el homicidio calificado es un "tipo autónomo" en relación con el homicidio simple $\mathrm{e}^{3}$. Y, no obstante el reflejo del homicidio calificado en conceptos con identidad cultural autónoma, se sigue tratando de una regla que parece caracterizarse por su heterogeneidad de un modo que sólo es compartido por reglas que enumeran agravantes. Superar la barrera de la heterogeneidad parece ser, por ello, un desafío importante.

El presente artículo tiene por objeto presentar una reconstrucción dogmática del artículo 391 número $1 \mathrm{CP}$ y de todas las formas de homicidios calificados que pueden encontrarse en el CP que dé cuenta de la lógica sistemática que le subyace. No pretende, en cambio, adentrarse en el nivel ulterior de análisis dogmático, a saber, constituir agrupaciones de casos que se dejan subsumir en cada una de las causales de calificación del homicidio. Su pretensión es antes presentar la lógica sistemática que subyace al conjunto.

Para ello, en primer lugar (1) intentaré describir aquello que puede ser denominado el acercamiento tradicional o exclusivamente semántico a la reconstrucción del homicidio calificado. De acuerdo a este modo de acercamiento, el estudio dogmático del homicidio calificado no podría más que reconocer la completa heterogeneidad que afecta al artículo 391 número 1 CP: toda pretensión sistemática estaría fuera de lugar. Su estudio sólo podría

\footnotetext{
${ }^{2}$ Sobre la significación del concepto en cuestión en la asunción del carácter autónomo del asesinato en la literatura española, véase sólo QUERALT JIMÉNEZ, Joan J., Derecho Penal Español. Parte Especial, 7. ed., Valencia: Tirant lo Blanch, 2015, p. 56; MUÑOZ CONDE, Francisco, Derecho Penal. Parte Especial, Valencia: Tirant lo Blanch, 2015, p. 41. En Chile véase POLITOFF, Sergio; GRISOLÍA, Francisco; BUSTOS, Juan, Derecho Penal Chileno. Parte Especial, Santiago: Editorial Jurídica de Chile, 2001, p. 113. También GARRIDO MONTT, Mario, El homicidio y sus figuras penales, Santiago: Ediciones Encina Limitada, 1976, p. 135 y s., destaca la relevancia histórica que ha tenido la diferenciación cultural de clases de homicidios.

${ }^{3}$ Entre nosotros así GARRIDO MONTT, Mario, Derecho Penal. Tomo III, $2^{\mathrm{a}}$ ed., Santiago: Editorial Jurídica de Chile, 2002, p. 52; BALMACEDA, Gustavo, Manual de Derecho Penal. Parte Especial, Santiago: Librotecnia, 2014, p. 31.
} 
WILENMANN, Javier. "El sistema de graduación de la pena del homicidio en el derecho chileno".

tener por objeto precisar los casos más o menos arbitrarios que componen a cada una de las variantes de homicidio calificado. Este acercamiento será contrapuesto con una aproximación histórico-sistemática construida sobre dos pilares: la especial dependencia de sentido de la institución "homicidio calificado" respecto de penas especificas a cuya imposición éste habilita (2); y la recepción de modelos de habilitación a la imposición de esa pena en los distintos ordenamientos occidentales (3).

Si bien ella solo es producida al final, la aplicación de los dos pilares a la regulación chilena (4) es la principal contribución de este artículo. El resultado de esta aplicación puede parecer extraña en el contexto de la literatura penal en Español, pero es la única interpretación correcta de un sistema como el chileno: el artículo concluye que, contra la asunción prácticamente unánime de la literatura nacional, el homicidio simple solo puede ser entendido como una forma privilegiada de homicidio calificado, a causa del reconocimiento de una "calificación" genérica en la forma de la premeditación. Dogmáticamente considerado ello trae consigo dos tareas adicionales que deben ser resueltas en este artículo. En primer lugar, la consagración de lo que será denominado un modelo mixto de regulación del homicidio calificado (con causal genérica y causales específicas) requiere de la clarificación de las relaciones entre la causal genérica (premeditación) y las causales específicas. En segundo lugar, la (completamente adecuada) amplitud del marco legal del artículo 391 número 1 CP implica que la dogmática del homicidio calificado tiene que concentrarse no sólo en problemas de calificación típica, sino también en la determinación de la pena al interior del marco. Explicar la lógica del sistema de graduación legal de la pena del homicidio en el derecho chileno y el modo en que debe razonarse dentro de éste es también una contribución que pretende realizar este artículo.

\section{El acercamiento tradicional.}

En su acercamiento al estudio del artículo 391 número $1 \mathrm{CP}$, la literatura chilena no parece ofrecer respuestas especialmente interesantes. Su estudio es realizado por medio de lo que uno podría denominar pura determinación semántica. Así, el acercamiento comienza con la pregunta por lo que caracteriza a un objeto tal como el veneno o a una promesa remuneratoria ${ }^{4}$, lo que tiende a ser complementado con consideraciones (más o menos convincentes) respecto a qué justifica la calificación en base al objeto así definido ${ }^{5}$. Este modo de acercamiento no es, por cierto, incorrecto en sí. Pero un estudio que se centre

\footnotetext{
${ }^{4}$ Así, por ejemplo, MATUS, Jean Pierre y RAMíREZ, María Cecilia, Lecciones de Derecho Penal Chileno. Parte Especial, 3. ed., Santiago: Legal Publishing, 2014, pp. 49 y ss.; LABATUT, Gustavo, Derecho Penal. Tomo II, $7^{\mathrm{a}}$ ed., Santiago: Editorial Jurídica de Chile, 1992, pp. 165 y ss.; BALMACEDA, Manual de Derecho Penal, cit nota $\mathrm{n}^{\circ} 3$, pp. 31 y ss. Similar aunque con una orientación histórica mucho más depurada POLITOFF, Sergio; GRISOLÍA, Francisco; BUSTOS, Juan, Derecho Penal Chileno. Parte Especial. Delitos contra el individuo en sus condiciones físicas, $2^{\mathrm{a}}$ ed., Santiago: Editorial Jurídica de Chile, 1993, pp. 115 y ss.

${ }^{5}$ En España tendencial BACIGALUPO, Enrique, Estudios sobre la Parte Especial del derecho penal, Madrid: Akal, 1991, pp. 28 y ss. Comparativamente, el estudio de Bacigalupo es dogmáticamente mucho más refinado que la mayoría de las exposiciones disponibles en español. Pese a ello, el estudio del derecho positivo se resuelve en la determinación complementaria de (i) el sentido de las distintas circunstancias calificatorias; y (ii) los motivos que pueden (o no), explicar la calificación. Similar GONZÁLEZ RUS, J.J., "El parricidio. El asesinato", en: COBO DEL ROSAL, Manuel (Ed.), Manual de Derecho Penal. Parte Especial I, Madrid: Editorial Revista de Derecho Privado, 1993, pp. 45-86 (pp. 59-61).
} 
exclusivamente en determinación semántica no sólo se enfrenta a la irreductible vaguedad del lenguaje, la que produce que sus conclusiones interpretativas no puedan resistir a la crítica por la posibilidad de incorporar otras condiciones o eliminar algunas de las condiciones propuestas, sino que asume desde un inicio que la labor central de reducción de la heterogeneidad del homicidio calificado no puede ser cumplida. Después de todo, si el estudio del homicidio calificado se reduce a precisar el sentido de las palabras que constituyen cada una de las circunstancias de calificación, entonces ello implica asumir que no hay correlación entre ellas.

Un acercamiento de esta clase puede ser constatado incluso en el que probablemente sigue siendo el estudio más relevante sobre el homicidio calificado en el derecho chileno, a saber, la sección correspondiente del Derecho Penal Chileno de Politoff, Grisolía y Bustos. Más allá de la excepcional conciencia histórica y comparada que el libro muestra en relación a otros trabajos producidos entre nosotros, su tratamiento general del homicidio calificado tiene una extensión de algo así como una página y media, centrada ante todo en la pregunta (ciertamente relevante) por el concurso de calificantes ${ }^{6}$. En el resto del estudio, su objetivo es precisar el sentido autónomo de cada una de las calificantes. El único momento en que se reflexiona sistemáticamente tiene lugar al preguntarse por la relación entre la premeditación y las demás calificantes ${ }^{7}$, lo que es respondido en apenas un párrafo de un modo inadecuado que mantiene la lógica de la completa autonomía entre calificantes.

La tesis que pretendo sostener aquí es que este es un acercamiento errado al estudio del homicidio calificado. La identidad conceptual y sistemática del estudio del homicidio calificado puede obtenerse, en cambio, a partir de la conjunción de dos factores: la fijación en la consecuencia jurídica que se sigue de su realización y la reconstrucción del modelo de justificación de la aplicación de esa consecuencia recogido por la legislación. En lo que sigue, exploraremos ambos aspectos, con el objetivo de construir un modo de acercamiento adecuado al homicidio calificado que pueda generar conciencia en los agentes del sistema penal - fiscales, defensores y jueces - del modo en que es necesario razonar al aplicar las reglas en cuestión.

\section{Pena y homicidio calificado.}

Contra las asunciones que subyacen al acercamiento tradicional al estudio del homicidio calificado, éste constituye una institución históricamente definida de un modo especialmente intenso por consideraciones que pueden denominarse unitarias. Con el concepto de consideraciones unitarias designamos aquí la posibilidad de atribuirle a una institución la pretensión de realización de un objetivo fácil y claramente delimitable. La estructuración de una institución en torno a una o varias consideraciones unitarias es un rasgo estructural que, en el discurso dogmático, es especialmente fructífero en la superación

\footnotetext{
${ }^{6}$ POLITOFF/GRISOLÍA/BUSTOS, Derecho Penal Chileno. Parte Especial. Delitos contra el individuo en sus condiciones fisicas, cit. nota $\mathrm{n}^{\circ}$ 4, p. 114 y s. Similar GARRIDO MONTT, El homicidio y sus figuras penales, cit. nota $\mathrm{n}^{\circ}$ 2, p. 139 y s.; ETCHEBERRY, Alfredo, Derecho Penal. Tomo III. Parte Especial., $3^{\mathrm{a}}$ ed., Santiago: Editorial Jurídica de Chile, 1998, p. 52 y s.

7 POLITOFF/GRISOLÍA/BUSTOS, Derecho Penal Chileno. Parte Especial. Delitos contra el individuo en sus condiciones físicas, cit. nota ${ }^{\circ}$ 4, p. 133.
} 
WILENMANN, Javier. "El sistema de graduación de la pena del homicidio en el derecho chileno".

de la heterogeneidad de un conjunto de reglas. Este es el caso del homicidio calificado: tanto en la tradición del derecho continental europeo como en el ámbito del common law, la regulación y tratamiento del homicidio calificado ha tendido a buscar un objetivo más bien preciso, a saber, determinar las condiciones de procedencia de la pena de muerte (o, antes, de formas calificadas de imposición de la muerte) por la realización de un homicidio ${ }^{8}$. En sistemas que no han abolido la pena de muerte, esta configuración unitaria de la institución se mantiene ${ }^{9}$. Ello se deja demostrar con relativa facilidad por referencia a la distinción norteamericana entre asesinato (murder) de primer y segundo grado, como veremos más adelante $^{10}$.

Lo anterior no quiere decir, por cierto, que la calificación del homicidio sólo tenga sentido como un modo de regulación de las condiciones de procedencia de la pena de muerte. El punto es mucho más sencillo: en sistemas en que la pena de muerte es aplicable, la necesidad institucional de determinación de condiciones precisas de aplicación de esta tiende a conectarse con la definición de un delito especialmente grave de homicidio. En el contexto de sistemas, como el nuestro, en que la pena de muerte ha sido abolida, la anomalía que constituye el mantenimiento del homicidio calificado ha tendido a encontrar una justificación directamente sustitutiva en la determinación de condiciones de procedencia del presidio perpetuo. Por ello, en sistemas como el nuestro que todavía prevén la aplicabilidad del presidio perpetuo, tener conciencia de esta función institucional es crucial para entender la importancia del homicidio calificado y el modo en que puede interpretarse el sistema de delitos de homicidio.

Esta sección tematiza estas tesis. En primer lugar demuestra - lo que no es especialmente difícil - la conexión histórica entre homicidio calificado (asesinato) y procedencia de la pena de muerte (2.1). Luego explica la sustitución que ha operado en varios sistemas, incluido el chileno, de la función de delimitación de la procedencia de la pena de muerte por el que fue construido políticamente como su equivalente humanitario o por su superación punitiva ("es mejor que el delincuente se pudra en la cárcel a que muera",11), en los dos discursos políticos que pueden escucharse a su respecto (2.2).

\footnotetext{
${ }^{8}$ En el derecho continental anterior a la codificación de fines del siglo XVIII y del siglo XIX, la función de la distinción entre homicidio calificado (Mord) y del homicidio tendía a ser la de determinar las condiciones de procedencia de modos de ejecución calificada (ie: especialmente dolorosa) de la muerte. Este es el caso, por ejemplo, de la Constitutio Criminalis Carolina en su artículo 137, la que siguiendo la tradición general del derecho alemán medieval, castigaba con la muerte a través de la rueda - una forma especialmente sádica de ejecución - al Mord. Al respecto véase SCHAFFSTEIN, Friedrich, Abhandlungen zur Strafrechtsgeschichte, Aalen: Scientia Verlag, 1986, p. 104 y s.; ESER, Albin, Empfielt es sich, die Straftatbestände des Mordes, des Totschlags und der Kindestötung (\$\$ 211 bis 213, 217 StGB) neu abzugrenzen. Gutachten D für den 53. Deutschen Juristentag; München: Beck, 1980, pp. 26 y ss.

${ }^{9}$ Entre nosotros, en tendencia similar MUÑOZ CONDE, Derecho Penal. Parte Especial, cit. nota n ${ }^{\circ} 2$, p. 41.

${ }^{10} \mathrm{El}$ concepto de murder y el concepto del que pretende diferenciarse (manslaughter) no pueden ser traducidos de un modo preciso al español. Aquí hemos distinguido entre asesinato y homicidio simple, pero ambos conceptos tienen reflejo en el lenguaje natural en inglés (assasination y homicide) que hacen que la distinción sea imprecisa. A diferencia del español, el inglés funciona aquí sobre la base de una distinción entre conceptos del lenguaje natural y conceptos legales. Precisamente por ello hemos elegido los conceptos jurídicos de asesinato (como reducción a una palabra del homicidio calificado) y homicidio simple.

${ }^{11}$ Sobre la utilización de esta clase de argumentos para justificar, "humanitariamente", el mantenimiento de la pena de muerte en Alemania a principios del siglo XX informa BVerfGE 45, 224.
} 
Polít. crim. Vol. 11, No 22 (Diciembre 2016), Art. 12, pp. 721-765.

[http://www.politicacriminal.cl/Vol_11/n_22/Vol11N22A12.pdf]

\subsection{El homicidio calificado como condición de habilitación a la imposición de la pena de muerte.}

Como hemos visto, la tesis de la que parte el reconocimiento del primer pilar en el estudio sistemático del homicidio calificado es la posibilidad de reconocer unidad de propósito en éste, en el sentido de la atribución de una función institucional dominante al menos en origen. Esta tesis se deja demostrar por simple referencia a la regulación del asesinato en la codificación así como por comparación con la distinción entre asesinato en primer y segundo grado en los Estados Unidos. Nos interesa, de este modo, revisar en primer lugar aquello que uno puede denominar unidad de propósito en su origen en la regulación del homicidio calificado su confirmación en sistemas que mantienen las circunstancias que justificaban esa unidad de propósito.

\subsubsection{El homicidio calificado en la codificación.}

En la legislación criminal materializada en la codificación, el establecimiento de formas de calificación del homicidio (más preciso: de diferenciaciones entre tipos básicos, calificados y privilegiados de homicidio) tenía por objeto diferenciar entre homicidios dolosos que hacían procedente (u obligatoria) la aplicación de la pena de muerte y homicidios dolosos en los que la pena de muerte no era procedente o al menos no era obligatoria. En la codificación europea, la regulación del homicidio calificado es así un modo de regular las condiciones de procedencia de la pena de muerte. Esto fue tomado, a su vez, por la codificación chilena.

Las fuentes que pueden ser invocadas en la demostración de esta tesis son múltiples y ella no debiera resultar polémica. Sólo por dar cuenta del texto de Códigos especialmente influyentes en nuestra tradición: este es el caso del Código Penal Francés de 1810, del Código Penal Bávaro de 1813 (Código de Feuerbach), del Código Penal Prusiano de 1851 y, a partir de éste, del Código Penal del Imperio Alemán de 1871, del Código Penal Belga de 1867, de los Códigos Penales Españoles de 1848 y 1870 y del Código Penal Chileno de $1874^{12}$. Salvo en el caso de los Códigos Penales Españoles de 1848 y 1870 y del Código Penal Chileno en su versión original, en lo esencial las distintas formas de calificación del homicidio implicaban la aplicación obligatoria de la pena de muerte. En el caso del Código Penal Chileno - cuyo texto, salvo en lo relativo a la pena, apenas ha sido modificado - la aplicación de la pena de muerte era obligatoria en el caso del parricidio y facultativa en el caso del homicidio calificado. En el caso del Código Penal Español de 1848, la aplicación de la pena de muerte sólo era obligatoria en caso de parricidios calificados - una técnica que tiene influencia hasta hoy en España - y facultativa en todos los demás casos de calificación (parricidio simple y asesinato). En el Código Penal de 1870 simplemente desapareció la regla de aplicación obligatoria de la pena de muerte.

Pese a las diferencias que expresa la técnica española y, en parte, la chilena respecto del resto de las legislaciones penales, todos los casos muestran un elemento común a la regulación de las distintas formas de calificación del homicidio: frente a aquello que puede

\footnotetext{
${ }^{12}$ En todo, véase el Anexo 1.
} 
WILENMANN, Javier. "El sistema de graduación de la pena del homicidio en el derecho chileno".

ser visto como homicidio simple - matar a otro con dolo -, la calificación tiene por objeto mandar o habilitar a la aplicación de la pena de muerte. La pena de muerte es, con ello, inaplicable (o facultativa) en los casos de homicidio simple, con lo que en la distinción entre homicidio simple y calificado se jugaba por completo la aplicabilidad de la pena de muerte. Ello supone la declaración de que no todo homicidio doloso contrario a derecho merece ser castigado con pena de muerte. Dependiendo del modelo de regulación - algo sobre lo que volveremos más adelante -, el homicidio calificado determinaba las condiciones positivas de merecimiento de la pena de muerte (modelo de la calificación) o las condiciones de no merecimiento de ésta (modelo del privilegio).

2.1.2. El homicidio calificado como condición excluyente de habilitación a la pena de muerte en el derecho norteamericano.

La relación entre aplicabilidad de la pena de muerte y homicidio calificado es todavía más fuerte en la legislación penal de los distintos Estados particulares en los Estados Unidos. Así, mientras en la codificación europea del siglo XIX, el homicidio calificado en sentido amplio habilitaba de modo excluyente a la aplicación de la pena de muerte solo si se consideraba el universo de delitos de homicidio, el derecho constitucional federal en los Estados Unidos apunta al reconocimiento de un efecto excluyente en la procedencia de la pena de muerte en el homicidio calificado respecto de todo el derecho penal común. Esto es: la pena de muerte solo puede ser impuesta por un delito común si se ha condenado por asesinato en primer grado (first degree murder) o asesinato capital (capital murder), dependiendo de la regulación estatal. Dar cuenta de esta tesis requiere de una pequeña explicación tanto de la lógica de la distinción entre clases de homicidio en el derecho norteamericano como de la evolución reciente de la jurisprudencia constitucional sobre pena de muerte.

En el derecho norteamericano es usual encontrar un sistema más complejo que en el derecho continental de graduación del homicidio. Partiendo de la distinción desarrollada en el common law inglés entre asesinato (murder) y homicidio simple (manslaughter) ${ }^{13}$, es usual que la legislación distinga entre asesinato en primer y en segundo grado (first $\mathrm{y}$ second degree murder); y homicidio simple voluntario o involuntario (voluntary/involuntary manslaughter). Algunos Estados particulares clasifican de modo todavía más parcelado las clases de homicidio, con el objeto de especificar todavía más las condiciones de aplicación de la pena máxima, al incluir un delito de asesinato merecedor de la pena máxima (capital murder).

Dadas las dificultades que la dogmática de la Parte General continental tiene al trazar una distinción entre imprudencia consciente y dolo eventual, y el enorme salto de pena que produce el paso de la punición por el delito doloso respecto de uno imprudente, es usual que la distinción entre asesinato de segundo grado y homicidio simple voluntario (voluntary manslaughter) y entre homicidio simple voluntario e involuntario reciba una buena dosis de atención, ya que ella es vista como un remedio posible de Parte Especial a un problema importante de Parte General que se presenta en el derecho continental. Precisamente a causa de esta fijación en la categoría del manslaughter como particularidad

\footnotetext{
${ }^{13}$ Sobre la distinción véase LaFAVE, Wayne, Criminal Law, $5^{\text {a }}$ ed., St. Paul: West Publishing, 2010, p. 765.
} 
Polít. crim. Vol. 11, No 22 (Diciembre 2016), Art. 12, pp. 721-765.

[http://www.politicacriminal.cl/Vol_11/n_22/Vol11N22A12.pdf]

del derecho anglosajón, es, sin embargo, usual que nuestra distinción entre homicidio simple y calificado sea analizada en relación a la distinción entre manslaughter y murder, con lo que necesariamente sólo se toma en consideración el asesinato en segundo grado al analizar el derecho norteamericano. Esto es lo que sucede incluso en el trabajo de Enrique Peñaranda Ramos sobre el asesinato. Al analizar la distinción entre homicidio simple y asesinato en el derecho norteamericano, Peñaranda salo se concentra en la distinción entre manslaughter y second degree murder, pese a reconocer acertadamente que la cuestión de la aplicabilidad de la pena de muerte se juega en la distinción entre asesinato de primer y segundo grado ${ }^{14}$.

Hacer equivalente la distinción entre homicidio simple y homicidio calificado del derecho continental con la distinción entre murder y manslaughter del derecho norteamericano es, sin embargo, dogmáticamente conflictivo. No es, por cierto, que se trate de un error conceptual: la inconmensurabilidad de sistemas hace que el trazado de equivalencias entre conceptos no pueda ser preciso. Ella es problemática, sin embargo, porque desconoce la equivalencia de funciones y de estructura entre el homicidio calificado continental y el first degree murder norteamericano. El derecho norteamericano es, en lo relativo al asesinato en primer grado, un reflejo vivo de la función original del homicidio calificado en el derecho continental, a saber, delimitar la aplicabilidad de la pena de muerte. Precisamente a causa de ello es que la distinción entre first y second degree murder es especialmente clarificadora al estudiar la función del homicidio calificado. Ello puede observarse con relativa facilidad estudiando la historia de la legislación del homicidio en los Estados Unidos y la jurisprudencia constitucional reciente sobre aplicabilidad de la pena de muerte en delitos comunes.

Comencemos con lo primero. La distinción entre los dos grados de asesinato fue producida históricamente con el objeto de regular la aplicación de la pena de muerte. La historia es relativamente sencilla: en la definición legada por el common law inglés, el asesinato (murder) era definido como homicidio cometido con "malicia preconcebida" (malice aforethought $)^{15}$, es decir, distinguía entre homicidio simple y asesinato de un modo similar al que lo hacía el gemeines Strafrecht bajo la Carolina o, en general, el derecho continental influido por la cultura jurídica romana. La evolución del common law y de la legislación inglesa hizo, sin embargo, que el concepto de malicia preconcebida perdiera su sentido original y se constituyera, en el fondo, en un término técnico que designaba todos los casos en que el common law trataba un homicidio como murder ${ }^{16}$.

Como la indeterminación del concepto de "malicia preconcebida" generaba falta de certeza, la pretensión de reserva y control de la aplicación de la pena de muerte se encontraba en conflicto con las categorías recibidas del common law. En los Estados particulares de las ex

\footnotetext{
${ }^{14}$ PEÑARANDA RAMOS, Enrique, Estudios sobre el delito de asesinato; Montevideo/Buenos Aires: BdeF, 2014, p. 44 y s.

${ }^{15}$ LaFAVE, Criminal Law, cit. nota ${ }^{\circ} 13$, p. 765.

${ }^{16}$ LaFAVE, Criminal Law, cit. nota ${ }^{\circ} 13$, p. 765 y s. Pese a la introducción de la distinción de grados en la gran mayoría de las jurisdicciones en los Estados Unidos, el concepto de malicia preconcebida mantiene vigencia en la definición del murder (de segundo grado), siendo su tratamiento una de las cuestiones centrales que aprenden los estudiantes de derecho penal. Al respecto KADISH, Sanford, SCHULHOFER, Stephen y STEIKER, Carol, Criminal Law and its Processes, $8^{\mathrm{a}}$ ed., New York: Aspen Publishers, 2007, p. 374 y s.
} 
WILENMANN, Javier. "El sistema de graduación de la pena del homicidio en el derecho chileno".

colonias británicas cuyas constituciones contenían limitaciones a la aplicación de la pena de muerte, este tratamiento era conflictivo. No es casual, por ello, que el desarrollo de la distinción entre dos formas de murder provenga de un Estado cuya constitución contenía disposiciones que ordenaban limitar racionalmente la aplicación de la pena de muerte: Pennsylvania. Realizando este mandato, la legislación de Pennsylvania estableció poco tiempo después de la Revolución Americana (1794) que la pena de muerte sólo procedería en caso de asesinato de primer grado, definiéndolo a partir del concepto general de premeditación (premeditation) e incluyendo otras circunstancias calificantes. Sólo el asesinato en primer grado habilitaría así a la imposición de la pena de muerte y éste se caracterizaría, en principio, por la premeditación; la inclusión de las otras circunstancias era de este modo una decisión por la aplicación de la pena de muerte. En cualquier caso, la creación del asesinato de primer grado en la legislación de Pennsylvania de 1794 tenía por objeto exclusivo regular la extensión de la aplicabilidad de la pena de muerte ${ }^{17}$.

La distinción entre asesinato de primer grado que habilita a la aplicabilidad de la pena de muerte y otras clases de homicidio se generalizó desde entonces, pese a que el contenido mismo del first degree murder tuviera su propia evolución. En general, la definición del first degree murder bajo el modelo del derecho común europeo de la premeditación fue complementada con circunstancias de calificación (equivalentes a nuestro veneno, alevosía, etc.). Las legislaciones particulares tienden así a trazar la distinción entre first degree murder y otras clases de homicidio doloso a través del desarrollo de aquello que denominaremos un modelo mixto ${ }^{18}$. En el derecho vigente en buena parte de los Estados particulares, el first degree murder (incluyendo aquí los casos de capital murder en jurisdicciones que gradúan en tres categorías al asesinato) no clausura, sin embargo, por completo la aplicación de la pena máxima correspondiente, ya que ésta tiende a ser aplicable también bajo la regla del denominado felony murder, esto es, el castigo como murder (incluyendo first degree murder, dependiendo de la legislación) del homicidio causado a propósito de la realización de algunos otros delitos graduados con felonies (robo, violación, secuestro, arson, etc.) ${ }^{19}$. Uno puede, por ello, reconocer un concepto de first degree murder en sentido amplio formado por dos subgrupos: el first degree murder estatutario y los casos a cuyo respecto procede la pena de muerte por aplicación de la regla del felony murder.

\footnotetext{
${ }^{17}$ AMERICAN LAW INSTITUTE, Model Penal Code and Commentaries Part II $\$ \$ 210.0$ to 213.6 ; Philadelphia: The American Law Institute, 1980, pp. 1, 16 y s.. KADISH/SCHULHOFER/STEIKER, Criminal Law and its Processes, cit. nota $\mathrm{n}^{\circ} 16$, p. 381.

${ }^{18}$ Infra. 31 y ss.

${ }^{19}$ Sobre el origen de la regla del felony murder LaFAVE, Criminal Law, cit. nota ${ }^{\circ} 13$, p. 785 y s.; AMERICAN LAW INSTITUTE, Model Penal Code, cit. nota $\mathrm{n}^{\circ}$ 17, p. 15 y s. Asumiendo un concepto amplio de first degree murder (o capital murder) como aquél que habilita a la imposición de la pena máxima, el felony murder puede ser considerado como tal. Es importante, sin embargo, distinguir el concepto estricto de este concepto ampliado, ya que el felony murder se encuentra sujeto no sólo a un tratamiento diferenciado de sus condiciones de procedencia, sino también a jurisprudencia constitucional sobre los casos en que resulta compatible con la aplicabilidad de la pena de muerte. Al respecto véase PALMER, Louis, The Death Penalty in the United States. A Complete Guide to Federal and State Laws, $2^{\mathrm{a}}$ ed., Jefferson, North Carolina: MacFarland \& Company, 2014, pp. 14 y ss.; CARTER, Linda, KREITZBERG, Ellen y HOWE, Scott, Understanding Capital Punishment, $3^{\mathrm{a}}$ ed., San Francisco: LexisNexis, 2012, pp. 98 y ss.
} 
Polít. crim. Vol. 11, No 22 (Diciembre 2016), Art. 12, pp. 721-765.

[http://www.politicacriminal.cl/Vol_11/n_22/Vol11N22A12.pdf]

Al mismo tiempo, el derecho norteamericano reconoce ciertas circunstancias que excluyen la aplicación sea sólo del first degree murder (y con ello de la pena de muerte) o incluso del murder en general y su recalificación como manslaughter. El caso más conocido a este respecto son las (polémicas) reglas sobre provocación ${ }^{20}$. El concepto amplio de first degree murder (o de capital murder, en los Estados que tienen graduaciones ulteriores del asesinato) engloba así todos los casos de murder que hacen procedente la pena máxima. Frente al homicidio intencional no sujeto a excusas del second degree murder, el first degree murder habilita a la imposición de la pena de muerte. La regulación de esta facultad es de este modo el objeto central de la categoría del asesinato en primer grado (o, en su caso, del asesinato capital) $)^{21}$.

Por supuesto, lo anterior no quiere decir que en todas las legislaciones estatales la aplicación de la pena de muerte se haya encontrado siempre limitada a los asesinatos en primer grado. En su origen, la categoría sólo pretendía determinar condiciones suficientes de imposición de la pena de muerte, pero varias legislaciones que adaptaron la distinción no excluían la posibilidad de aplicarla en otros casos. Este era el caso tratándose especialmente de delitos sexuales y, dentro de esta categoría, de violaciones de menores de edad ${ }^{22}$. Pese a ello, el sistema norteamericano parece acercarse progresivamente a identificar una categoría ampliada de asesinato en primer grado (incluyendo aquí al felony murder) como condición ya no sólo suficiente sino necesaria de la imposición de la pena de muerte por la realización de delitos comunes. Así se desprende de la jurisprudencia constitucional reciente de la Corte Suprema Federal.

Tras la confirmación en Gregg v. Georgia ${ }^{23}$ de que la pena de muerte no había sido declarada inconstitucional en sí en Furman v. Georgia ${ }^{24}$, la Corte Suprema Federal inauguró un período de apreciación relativa (es decir: no planteando la pregunta de si la pena de muerte es per se incompatible con la Constitución Federal, asumiendo que la respuesta a esta pregunta es negativa) de la constitucionalidad de la pena de muerte, controlando la proporcionalidad respecto a delitos específicos, respecto de ciertas clases de condenados particulares (individuos con alguna enfermedad mental que no excluya la culpabilidad; menores de edad) y respecto del modo de aplicación de ésta ${ }^{25}$. El caso inaugural de la línea que nos interesa - sobre proporcionalidad respecto a la clase de delito por el que se condena

\footnotetext{
${ }^{20} \mathrm{Al}$ respecto KADISH/SCHULHOFER/STEIKER, Criminal Law and its Processes, cit. nota ${ }^{\circ} 16$, pp. 390 y ss.

${ }^{21}$ Así explícitamente LaFAVE, Criminal Law, cit. nota ${ }^{\circ}$ 13, p. 809. Aunque la regulación del Model Penal Code se aleja intencionalmente de este modelo, ella mantiene las dos consideraciones centrales que animan en su espíritu al modelo general del derecho norteamericano: (i) expresar mediante la distinción entre murder y manslaughter las diferencias contextuales de las que pueden ser expresivas acciones homicidas respecto a la vida ajena - con ello mantiene en el fondo un modelo de privilegio -; y (ii) la necesidad de regulación particular de la pena de muerte, regulando en su $§ 210.6$ condiciones especialmente detalladas de imposición de ésta, asumiendo la necesidad de que en cualquier caso haya condena por murder.

${ }^{22}$ De acuerdo a Palmer, p. 16s., entre 1930 y 1968, de un total de 3859 aplicaciones de pena de muerte, 3334 tuvieron lugar por delitos involucrando homicidios, 455 por violación y 70 por otros delitos.

${ }^{23}$ Gregg v. Georgia, 428 U.S. 153 (1976).

${ }^{24}$ Furman v. Georgia, 408 U.S. 238 (1972).

${ }^{25}$ Véase en general CARTER/KREITZBERG/HOWE, Understanding Capital Punishment , cit. nota $\mathrm{n}^{\circ} 19$, pp. 108 y ss.
} 
WILENMANN, Javier. "El sistema de graduación de la pena del homicidio en el derecho chileno".

- es Coker v. Georgia ${ }^{26}$. En Coker, la Corte declaró inconstitucional la aplicación de la pena de muerte en un caso de pura violación pese a que hubiera una condena previa del autor por homicidio en primer grado. Como la condena era previa, la regla del felony murder no era aplicable, por lo que la pena de muerte necesitaba justificarse como proporcional pese a su desconexión con cualquier clase de homicidio. La Corte negó la constitucionalidad de la pena de muerte respecto de delitos de violación de adultos. Coker sólo dejó claro, de este modo, que la imposición de pena de muerte por la pura violación de adultos resultaba incompatible con la Constitución Federal. La Corte no resolvió, en cambio, si la pena de muerte resultaba constitucional en otros casos de delitos sin homicidio. La pregunta permaneció abierta ante todo en los casos de violación de menores de edad, respecto a los cuales varios Estados mantenían la posibilidad de aplicar la pena de muerte incluso después de Coker.

La cuestión fue zanjada, sin embargo, por la Corte Suprema Federal en el año 2008 en una votación sumamente dividida y políticamente polémica: el caso Kennedy v. Louisiana ${ }^{27}$. En el caso en cuestión, la Corte no sólo estableció la inconstitucionalidad de la imposición de la pena de muerte respecto de la violación de menores, sino que declaró explícitamente que en delitos contra intereses individuales, su imposición sólo sería constitucional si la vida de la víctima "fue tomada". Es decir, la aplicabilidad de la pena de muerte presupondría constitucionalmente que el delito por el que se la impone incluya un homicidio. Conforme a la interpretación actual de la Corte Suprema Federal de la Constitución de los Estados Unidos, la aplicación de la pena de muerte por un delito común (p. ej.: excluyendo cuestiones excepcionales como la traición) presupone así que el hecho por el que ésta se impone implique un homicidio ${ }^{28}$.

Por supuesto, de esta afirmación no se sigue inmediatamente que sólo en el caso del asesinato de primer grado proceda la pena de muerte. Pero como la distinción de grados es utilizada para marcar la distinción entre homicidios en que procede la pena de muerte asesinato de primer grado en sentido amplio - respecto a casos en que no procede, ello implica en el fondo reducir en los hechos la aplicabilidad de la pena de muerte a los asesinatos de primer grado en sentido amplio. El derecho penal nuclear norteamericano esto es, con exclusión de traiciones, espionajes y otras cuestiones posibles de Estado y criminalidad organizada no descartadas por la Corte Suprema Federal en Kennedy - limita así la aplicabilidad de la pena de muerte al first degree murder en sentido amplio. Su regulación es, en ese sentido, una determinación excluyente de las condiciones de aplicación de la pena de muerte en delitos comunes. La función institucional de las reglas de asesinato de primer grado es, en ese contexto, obvia: se trata simplemente de la regulación de la procedencia de la pena de muerte.

\footnotetext{
${ }^{26}$ Coker v. Georgia, 433 U.S. 584 (1977).

${ }^{27}$ Kennedy v. Louisiana, 554 U.S. 407 (2008).

${ }^{28}$ Así también PALMER, The Death Penalty in the United States, cit. nota ${ }^{\circ} 19$, p. 17 y s. Por supuesto, la extensión de esta limitación constitucional depende del sentido que se le dé a la categoría de delitos comunes o exclusivamente contra las personas, respecto a las cuales la Corte Suprema Federal formuló la regla: Kennedy v. Louisiana, 554 U.S. 407, 438 (2008). Ello dejó explícitamente abierta la posibilidad de aplicación en casos que involucren intereses estatales, pero también tratándose de criminalidad organizada. Véase también CARTER/KREITZBERG/HOWE, Understanding Capital Punishment, cit. nota n 19, pp. 124 y ss.
} 
Polít. crim. Vol. 11, No 22 (Diciembre 2016), Art. 12, pp. 721-765.

[http://www.politicacriminal.cl/Vol_11/n_22/Vol11N22A12.pdf]

\subsection{El homicidio calificado tras la derogación de la pena de muerte.}

2.2.1. Presidio perpetuo y homicidio calificado tras la derogación de la pena de muerte.

Con la abolición de la pena de muerte, la función institucional del homicidio calificado ya no puede por definición vincularse a la regulación de las condiciones de imposición de la pena de muerte. Los sistemas continentales han tendido, sin embargo, a mantener la distinción entre homicidio simple y homicidio calificado pese a la abolición de la pena de muerte. Ello muestra que su función institucional debe ser otra.

Una observación relativamente superficial de los sistemas más influyentes muestra que ese cambio ha operado por vía de substitución más o menos directa: allí donde el homicidio calificado regulaba la aplicación de la pena de muerte, éste regula ahora la aplicación del presidio perpetuo. Esto es obvio en el Código Penal Francés, en el Código Penal Alemán o en el Código Penal Italiano, cuyos tipos respectivos prevén sólo la aplicación del presidio perpetuo a casos de homicidio calificado ${ }^{29}$. Pero también el Código Penal Suizo y el Código Penal Austriaco hacen procedente, aunque de modo facultativo, la aplicación del presidio perpetuo en casos de homicidio calificado y no así en casos de homicidio simple. La excepción la constituye nuevamente el Código Penal Español, el que desde la reintroducción de la prisión permanente revisable mediante la reforma de 2015 sólo hace procedente el presidio perpetuo en delitos comunes (p.ej.: excluyendo homicidio del jefe de Estado, genocidio, delitos de lesa humanidad, etc.) tratándose de asesinatos calificados (art. 140). Esta doble calificación no implica, en el fondo, más que la adopción de un sistema de tres grados de homicidio doloso, con lo que en realidad sólo es una excepción aparente.

Lo anterior muestra que bajo el derecho vigente de buena parte de los ordenamientos jurídicos continentales, el homicidio calificado sigue siendo una institución regulatoria de una pena que asume una naturaleza peculiar, pese a que la distinción haya perdido importancia con la abolición de la pena de muerte.

Por supuesto, la constatación de la existencia de esta función no implica que la única función que puede cumplir el homicidio calificado sea regular la imposición de una pena categóricamente diferenciable de las penas que, en gravedad, le siguen, y que con la eventual derogación del presidio perpetuo, el homicidio calificado haya dejado de ser una institución justificable. La afirmación de que el sentido del homicidio calificado es otro en sistemas que prevén la aplicabilidad de la pena de muerte o del homicidio calificado, no pretende desconocer que la gravedad de esta clase de delitos es graduable con

\footnotetext{
${ }^{29}$ Esta previsión absoluta de procedencia de privación perpetua de libertad es, por cierto, sumamente criticada en la literatura y explica la introducción de criterios ad-hoc de revisión en la jurisprudencia. Sobre ello volveremos de inmediato. Críticas a la procedencia sin más de la prisión perpetua (y, antes, de la pena de muerte) en caso de Mord pueden encontrarse en ESER, Empfielt es sich, die Straftatbestände des Mordes, cit. nota $\mathrm{n}^{\circ}$ 8, pp. 29 y s., 35 y ss.; HEINE, Günther et al., "Alternativ-Entwurf Leben (AE-Leben)", Goltdammer's Archiv für Strafrecht, 193-270 (2008), pp. 196 y ss., 212 y ss.; SALIGER, Frank, "Grundfragen einer Reform der Tötungsdelikte", Zeitschrift für die internationale Strafrechtsdogmatik, 2015, 600-604 (p. 602).
} 
WILENMANN, Javier. "El sistema de graduación de la pena del homicidio en el derecho chileno".

independencia de la pena que proceda ${ }^{30}$, sino sólo pretende dar cuenta de que esta graduación es cualitativamente más relevante en sistemas que sí contemplan estas penas.

2.2.2. El presidio perpetuo como primer pilar de estructuración de la dogmática del homicidio calificado. ¿Estudio dogmático del homicidio calificado como reflexión sobre las condiciones sustantivas de justificación de la imposición del presidio perpetuo?

En los sistemas jurídicos continentales contemporáneos, incluyendo, como veremos, al chileno, las reglas de calificación del homicidio habilitan a la imposición del presidio perpetuo. El primer pilar en el que debe basarse su reconstrucción dogmática es, de este modo, la pura conciencia de que esto es lo que institucionalmente se juega al discutir sobre la calificación del homicidio.

La relevancia de la regulación de la procedencia del presidio perpetuo en el tratamiento del homicidio calificado es algo que ha sido advertido con especial claridad en la discusión constitucional, dogmático penal y político criminal en Alemania. Esto tiene una explicación institucional: el sistema alemán prevé la aplicabilidad absoluta (p.ej.: sin alternativas) del presidio perpetuo para el homicidio calificado $(\text { Mord })^{31}$. Esto es una (muy pesada) herencia del modo en que se realizó la abolición de la pena de muerte en el sistema jurídico alemán. Al igual que en buena parte de los ordenamientos occidentales, la República Federal Alemana abolió la pena de muerte en la segunda mitad del siglo XX, reemplazando su

\footnotetext{
${ }^{30}$ Similar ESER, Empfielt es sich, die Straftatbestände des Mordes, cit. nota ${ }^{\circ}$ 8, pp. 106 y ss.: la abolición de la pena de muerte hace desaparecer la necesidad de una regulación categóricamente diferenciadora del Mord. También KÖHLER, Michael, "Zur Abgrenzung des Mordes”, Goltdammer's Archiv für Strafrecht, 1980, 121-42 (p. 121): la función del homicidio calificado sería regular ciertamente la aplicación de la pena más alta del sistema, con independencia de que sea un modo de ejecución especialmente intenso de la pena de muerte, la simple pena de muerte, el presidio perpetuo o un presidio temporalmente limitado. Menos precisos PEÑARANDA RAMOS, Estudios sobre el delito de asesinato, cit. nota ${ }^{\circ} 14$, pp. 66 y ss., BACIGALUPO, Estudios sobre la Parte Especial, cit. nota n ${ }^{\circ}$ 5, p. 33; MORALES PRATS, Fermín, “Art. 138-140”, en: QUINTERO OLIVARES, Gonzalo y MORALES PRATS, Fermin (Eds.), Comentarios al Código Penal.

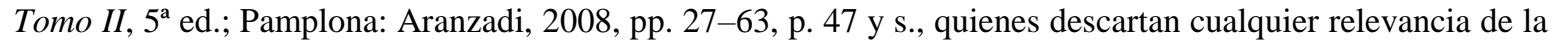
antigua función de delimitar la procedencia de la pena de muerte y lo tratan como una "simple explicación histórica". Esta es una asunción que puede encontrarse en la literatura española desde el Código Penal de 1848. Así ya PACHECO, Joaquín Francisco, El Código Penal Concordado y Comentado. Tomo III, $2^{\mathrm{a}}$ ed., Madrid: Imprenta de la viuda de Perinat y compañía, 1856, pp. 21 y ss., se concentraba en la exaltación del carácter horrible de los casos incluidos como homicidios calificados (y también, por cierto, del parricidio), antes que dar cuenta de su función reguladora de la aplicabilidad de la pena de muerte. A su época ello ya tenía, sin embargo, una explicación: como hemos visto, salvo en el caso del parricidio calificado, la aplicación de la pena de muerte (y luego del presidio perpetuo) ha tendido a ser facultativo en la tradición española. La regulación del homicidio calificado ha sido así menos relevante históricamente en la tradición española que en el resto de los ordenamientos jurídicos occidentales, en que es usual que la aplicación de la pena máxima sea obligatoria o sólo pueda ser excepcionalmente evitada. Eso no quiere decir que sea una necesidad solamente histórica; la necesidad de diferenciación categórica ciertamente depende de la procedencia absoluta de la pena de muerte o, sustitutivamente, del presidio perpetuo. La graduación de la pena del homicidio debe seguir siendo, sin embargo, sensible a las particularidades de la pena específica que permite imponer si ella incluye, como ahora también en España, el presidio perpetuo.

${ }^{31}$ Ello sería constitutivo del "mal original" que ha impulsado tanto las discusiones sobre reforma como la extraña dogmática del Mord en Alemania. Así ESER, Empfielt es sich, die Straftatbestände des Mordes, cit. nota $\mathrm{n}^{\circ}$ 8, p. 63; HEINE, Günther, "Stand und Entwicklung der Mordtatbestände", en: KREUZER, Arthur et al. (Eds.), Ehrengabe für Anne-Eva Brauneck; Mönchengladbach: Forum Verlag Godesberg, 1999, pp. 315-52 (p. 318).
} 
procedencia por el presidio perpetuo. El caso más relevante de aplicabilidad del presidio perpetuo se ve constituido, por ello, precisamente por el delito que paradigmáticamente habilitaba a la imposición de la pena de muerte, a saber, el homicidio calificado (Mord). Al momento de abolir la pena de muerte, el derecho alemán simplemente sustituyó su aplicabilidad por aquella del presidio perpetuo, lo que significó el mantenimiento de la procedencia absoluta del presidio perpetuo en los tipos en que procedía de modo absoluto la pena de muerte. Por ello, no es casual que la discusión sobre la constitucionalidad del presidio perpetuo haya tenido lugar justamente a propósito de la disposición que tipifica el Mord ( $\$ 211$ del Código Penal alemán, en adelante "StGB”).

En el año 1977, el Tribunal Constitucional Federal controló la constitucionalidad del presidio perpetuo y de las disposiciones que disponen su aplicación por homicidios cometidos con el fin de esconder la realización de otro delito (Verdeckungsabsicht) o con alevosía (Heimtücke) ${ }^{32}$. El Tribunal Constitucional sostuvo que tanto la pena en sí $^{33}$ como su aplicación en los casos de homicidio calificado eran compatibles con la Ley Fundamental siempre que se cumplieran dos condiciones:

1) Que el sistema previera la revisión en etapa de ejecución de la necesidad de continuar aplicando la pena de presidio, transcurrido que hubiera un período determinado de tiempo $^{34} ; \mathrm{y}$

2) que la interpretación de las distintas causales de calificación del homicidio tuviera lugar de modo tal que fuera posible afirmar que en todos sus casos la aplicación del presidio perpetuo sea proporcional ${ }^{35}$.

Esto puede no parecer nada más que una explicitación del criterio que, en los hechos, estructura institucionalmente al homicidio calificado en Alemania: la posibilidad de apreciar una justificación suficiente de la aplicación de la pena excepcional y máxima del sistema a causa de la previsión absoluta del presidio perpetuo. Lo problemático - aunque probablemente inevitable ${ }^{36}$ - de este modo de proceder, es el hecho de que este principio

\footnotetext{
${ }^{32}$ BVerfGE 45, 187. En lo relativo a su significación para la dogmática del homicidio calificado en Alemania, Günther Heine designaba a esta decisión como "decisión de una era" (Epochenentscheidung), HEINE, "Stand und Entwicklung der Mordtatbestände”, cit. nota $n^{\circ}$ 31, p. 318. En los hechos, tanto la discusión dogmática como la discusión política criminal ha estado dominada por las consideraciones establecidas en la decisión.

${ }^{33}$ BVerfGE 45, 229 y ss.

${ }^{34}$ BVerfGE 45, 238 y ss. Pese a que la exigencia parece sensata al punto de la necesidad, la necesidad de revisión después de un período determinado puede cambiar la naturaleza de la pena de presidio perpetuo: si la liberación condicional procede salvo en casos de peligro calificado, el mantenimiento de la ejecución pena después de que se cumpla ese primer período se convierte, en los hechos, en una custodia de seguridad. Esto es especialmente probable en sistemas que no tengan instituciones de esta clase.

${ }^{35}$ BVerfGE 45, 261.

${ }^{36}$ El carácter inevitable de este modo de proceder es descrito así por NEUMANN, Ulfried, "Vor $\S 211 "$, en: KINDHÄUSER, Urs; NEUMANN, Ulfried y PAEFFGEN, Hans-Ullrich (Eds.), Nomos Kommentar Strafgesetzbuch, $4^{\mathrm{a}}$ ed.; Baden-Baden: Nomos, 2013, pp. 1511-83 (Nm. 157 y s.), por referencia a BGHSt 40, 360: como acciones con una variedad importante de disvalor de acción y resultado pueden ser subsumidos en el $\S 211$ StGB y esa diferencia no puede expresarse en la determinación de la pena, ello debe tener lugar en el plano de la interpretación de los tipos. Más precisamente debiera decirse, sin embargo, que no siempre parece adecuado aplicar el presidio perpetuo a toda acción que se deje subsumir en el $§ 211 \mathrm{StGB}$.
} 
WILENMANN, Javier. "El sistema de graduación de la pena del homicidio en el derecho chileno".

institucional exhiba desde entonces una tendencia a convertirse directamente en criterio de interpretación dogmático. Sobre ello volveremos de inmediato.

Desde el fallo del Tribunal Constitucional Federal, el caso que paradigmáticamente ha servido al control de la capacidad del sistema de adaptar la aplicación del homicidio calificado a estas limitaciones, ha sido el muy significativo caso criminológico del homicidio del marido maltratador por su mujer. Aquí se trata de un caso en que los tribunales sin competencia constitucional saben la conclusión a la que deben llegar - no puede aplicarse el presidio perpetuo, porque no se justifica - pero tienen enormes dificultades en justificarlo mediante razonamiento formal. Es decir: el derecho vigente parece forzarles a aplicar el presidio perpetuo, ya que el modelo legislativo prevé de modo absoluto su procedencia en caso de realizarse el homicidio doloso en una de las circunstancias calificadas (aquí, en general: alevosía). Pero, al mismo tiempo, la pena no parece ser en abstracto proporcional y con ello vulneraría las exigencias del Tribunal Constitucional Federal. La jurisprudencia y dogmática deben, por ello, proveer una explicación de las razones por los que pese a la apariencia clara de aplicabilidad del Mord, este no es en realidad aplicable a esos casos.

Las dos "teorías" que se han desarrollado para justificar la conclusión a la que se quiere llegar asumen esta tarea. Conforme a la teoría de la "corrección negativa del tipo"37, se encontraría excluida la aplicación del tipo de Mord en los casos en que el homicidio pone fin a una situación de maltrato reiterado o en otras circunstancias de inadecuada aplicación. En cambio, conforme a la "teoría de la determinación de la pena" (Rechtsfolgenlösung, literalmente: teoría de la consecuencia jurídica), sería inevitable reconocer la realización imputable del tipo del Mord en buena parte de los casos a cuyo respecto la aplicación resulta inadecuada, por lo que en estos casos sería necesario reconocer facultades excepcionales de aplicación de una pena por debajo del marco ${ }^{38}$. Por supuesto, ninguna de las dos "teorías" debiera ser llamada como tal: se trata simplemente de un modo de insertar una conclusión establecida de antemano o bien en el tipo o bien en la determinación de la pena. Se trata, en ese sentido, de pura aplicación del criterio de control material en la interpretación del homicidio calificado, a saber, la posibilidad de justificar concretamente la aplicación del presidio perpetuo ${ }^{39}$.

\footnotetext{
${ }^{37}$ Con más detalle SCHNEIDER, Hartmut, “§ 211”, en: JOECKS, Wolfgang y MIEBACH, Klaus (Eds.), Münchener Kommentar Strafgesetzbuch Band 4, 2a ed.; München: C.H. Beck, 2012, pp. 467-635 (Nm. 35 y ss.); NEUMANN, "Vor $\S 211$ ", cit. nota n 36 (Nm. 159 y ss.).

${ }^{38}$ Véase WESSELS, Johannes; HETTINGER, Michael, Strafrecht Besonderer Teil 1, 39. ed.; Heidelberg: C.F. Müller, 2015, § 2 Nm. 75 y s.

${ }^{39}$ Correctamente designada como estrategias (sustantivamente adecuadas) de elusión en la aplicación de la ley (Umgehungstechnik) por HEINE et al., "Alternativ-Entwurf Leben (AE-Leben)", cit. nota n 29, p. 197 y s.; HEINE, "Stand und Entwicklung der Mordtatbestände", cit. nota $\mathrm{n}^{\circ}$ 31, p. 324 y s. Sobre las estrategias "restrictivas" de la aplicación del Mord presentes en jurisprudencia y literatura véase SCHNEIDER, "§ 211", cit. nota $\mathrm{n}^{\circ} 37$ (Nm. 23ff.); ESER, Albin; STERNBERG-LIEBEN, Detlev, "§ 211”, en: ESER, Albin (Ed.), Schönke/Schröder Strafgesetzbuch Kommentar, 29a ed.; München: C.H. Beck, 2014, pp. 2031-53 (Nm. 9 y ss.); SAFFERLING, Christoph, "§ 211", en: MATT, Holger; RENZIKOWSKI, Joachim (Eds.), Strafgesetzbuch Kommentar, München: Verlag Franz Vahlen, 2013, pp. 1624-54 (Nm. 2); WESSELS/ HETTINGER, Strafrecht Besonderer Teil 1, cit. nota $\mathrm{n}^{\circ} 38$, 2 Nm. 86ss.; HEINE, "Stand und Entwicklung der Mordtatbestände", cit. nota n $^{\circ} 31$, pp. 325 y ss.
} 
Polít. crim. Vol. 11, No 22 (Diciembre 2016), Art. 12, pp. 721-765.

[http://www.politicacriminal.cl/Vol_11/n_22/Vol11N22A12.pdf]

El ejemplo alemán pone de relieve tanto para bien como para mal la importancia de la conciencia que se tenga sobre el rol institucional del homicidio calificado. La advertencia en sí del Tribunal Constitucional Federal puede considerarse positiva. Problemática es, sin embargo, la aplicación de la segunda condición de constitucionalidad establecida por el BVerfG. Ella puede ser vista como una exigencia de orientación moral total en la interpretación del $\S 211$ StGB. Esto puede parecer sensato: si la función institucional de la distinción entre homicidio calificado y homicidio simple es regular la aplicación del presidio perpetuo, parece razonable afirmar que el primer pilar sobre el que debe fundarse una reconstrucción dogmática del homicidio calificado es el establecimiento de condiciones sustantivas de legitimación de la aplicación del presidio perpetuo. El BGH ha tendido a estructurar su tratamiento del homicidio calificado de este modo: su aplicación requeriría una ponderación total (Gesamtabwägung) de los elementos del hecho en relación con las calificantes del homicidio, para determinar si éste presenta un grado de reproche (Verwerflichkeit) tal que justifique la aplicación del presidio perpetuo ${ }^{40}$.

Esto, por supuesto, no puede ser así: se trata de la interpretación de una regla de derecho y no, en cambio, de reflexión moral o política directa. Interpretar de este modo la segunda regla formulada por el BVerfG solo puede conducir a errores metodológicos, en el sentido de introducir modos de razonamiento incompatibles con la sujeción al derecho positivo. Antes, la segunda regla formulada por el BVerfG debe interpretarse como una pura advertencia sobre la necesidad de realizar un control teleológico excepcional. Esto es: no se trata de reemplazar las circunstancias legislativamente constituidas de calificación del homicidio por una apreciación moral directa (la Gesamtabwägung) del grado de reproche del homicidio, sino sólo de tener conciencia de que en casos en que la aplicación sea manifiestamente inadecuada, no puede exigirse simplemente tener "dureza de corazón" y optar por aplicar el presidio perpetuo pese a su inadecuación. Esto no es algo que, en cualquier caso, nos afecte demasiado a nosotros, ya que el CP no prevé la aplicación absoluta, sin alternativas, del presidio perpetuo, y la incorporación de consideraciones de esta clase en una dogmática de la determinación de la pena no tiene nada de inadecuado. Sí es importante, sin embargo, tener conciencia de la relevancia de la formulación de criterios de determinación de la pena en este caso.

Nada de esto tiene potencial de rendimiento, sin embargo, en la reconstrucción sistemática de la calificación del homicidio. La función institucional del homicidio calificado es así ciertamente la de regular la procedencia del presidio perpetuo, pero el modo de realización de este objetivo tiene lugar a partir de un sistema de reglas explícitas de calificación. En general, la función institucional de las reglas no debe servir como argumento para la interpretación de las reglas. Convertir a la dogmática del homicidio calificado en una Gesamtabwägung del hecho para valorar directamente la razonabilidad moral de la aplicación del presidio perpetuo es un error metodológico decisivo. Pero ello parece dejarnos sin apoyo: la conciencia de la función institucional del homicidio calificado permitiría entender la institución, pero no hemos ganado nada en relación al reconocimiento de bases en su reconstrucción interpretativa.

\footnotetext{
${ }^{40}$ Similar en su apreciación crítica KÖHLER, “Zur Abgrenzung des Mordes”, cit. nota n 30, pp. 126 y ss.
} 
WILENMANN, Javier. "El sistema de graduación de la pena del homicidio en el derecho chileno".

La demostración del vínculo existente entre presidio perpetuo y homicidio calificado parece con ello devolvernos al principio de nuestra investigación. Por cierto: ahora tenemos conciencia de que no se trata de una institución irrelevante y que ella se encuentra vinculada a una finalidad específica. Pero la identificación de esta función es, en la mejor interpretación del modo en que funciona la dogmática del homicidio calificado en el derecho alemán, un criterio de control de interpretación y, en nuestro caso, un criterio relevante en la determinación de la pena y no así en la calificación típica. ¿Significa esto que, en el resto, debemos volver al modo normal de razonamiento puramente semántico sobre el homicidio calificado para reconstruir interpretativamente los tipos? Como veremos a continuación, ello no es así. El homicidio calificado en su estructuración chilena ofrece posibilidades de razonamiento sistemático especialmente fructíferas, las que no han sido aprovechadas para realizar una reconstrucción racional del tipo.

\section{La dogmática del homicidio calificado.}

\subsection{Bases de una dogmática del homicidio calificado.}

Como hemos visto, la función institucional del homicidio calificado es la determinación de las condiciones de procedencia de un castigo sustancialmente más intenso que en el caso de los homicidios simples. Si bien esta es su función institucional, ella no sirve en la construcción de una dogmática del homicidio calificado más que como un principio de control de extrema inadecuación en la aplicación. Como fundamento sistemático general de análisis de una institución que, como también hemos visto, se caracteriza por su heterogeneidad, la función institucional debe ser inservible. ¿Cómo puede construirse, entonces, la dogmática del homicidio calificado sin caer en la pura determinación semántica o en la argumentación moral?

Una respuesta posible puede venir dada por reflexión respecto a las condiciones que justifican una calificación de un homicidio que de por sí afecta el bien jurídico de mayor relevancia desde un punto de vista personal. Al interpretar las distintas circunstancias de calificación, la pregunta central sería: ¿cómo puede ser que esta circunstancia permita apreciar una mayor necesidad/merecimiento de pena respecto de un homicidio simple? Aquí no se trata de la conversión del razonamiento sobre el tipo en una Gesamtabwägung, sino más bien en la orientación en la interpretación de las causales mediante su análisis legitimatorio directo. No se trata así de reflexión sobre la pregunta desnuda "¿en qué condiciones es especialmente grave un homicidio?”, sino sobre preguntas del tipo "¿qué hace de la alevosía un medio comisivo especialmente reprochable del homicidio y cuándo se presenta este especial reproche?"

Este modo de acercamiento goza de cierta popularidad en la dogmática penal alemana ${ }^{41}$ y en los mejores estudios sobre el homicidio calificado disponibles en nuestra tradición ${ }^{42}$.

\footnotetext{
${ }^{41}$ De este modo procede (con mayor o menor acierto), en general, la literatura de manuales y comentarios. Así SCHNEIDER, “\$ 211”, cit. nota n³7 (Nm. 6 y ss.); SAFFERLING, “§ 211”, cit. nota n 39 (Nm. 3).

${ }^{42}$ Clara orientación en este sentido en BACIGALUPO, Estudios sobre la Parte Especial, cit. nota n ${ }^{\circ} 5$, pp. 28 y ss.; GONZÁLEZ RUS, "El parricidio. El asesinato", cit. nota n 5, p. 60 y s.; GONZÁLEZ RUS, J.J., “Artículos 139-140", en: COBO DEL ROSAL, Manuel (Ed.), Comentarios al Código Penal. Tomo V; Madrid: Edersa, 1999, pp. 121-57 (pp. 125 y ss.). MORALES PRATS, “Art. 138-140”, cit. nota n 30, p. 47
} 
Polít. crim. Vol. 11, No 22 (Diciembre 2016), Art. 12, pp. 721-765.

[http://www.politicacriminal.cl/Vol_11/n_22/Vol11N22A12.pdf]

Dependiendo de la propia concepción del derecho penal que tenga el autor en cuestión - a grandes rasgos: prevencionista o retribucionista -, el estudio tiende a enfocarse entonces a determinar en qué sentido las circunstancias expresan mayor necesidad preventiva de pena o mayor merecimiento de reproche.

Desde un punto de vista prevencionista, las respuestas disponibles son dos: el homicidio calificado daría cuenta de mayor necesidad preventivo especial, en el sentido de que el hecho revelaría una mayor peligrosidad de base del autor; o las circunstancias debieran revelar mayor necesidad preventivo general. Pese a su verosimilitud como explicación de origen - alevosía, premeditación, promesa remuneratoria y veneno dan cuenta de disposición a matar en base a una decisión fría; y el ensañamiento da cuenta de una particular propensión a la violencia -, el primer acercamiento tiende a ser desechado por ser incompatible con un derecho penal del hecho y no del autor ${ }^{43}$. El derecho penal debiera orientarse a la protección de bienes jurídicos y no al tratamiento de sujetos que puedan ser considerados peligrosos. A partir de esta diagnóstico, tiende a advertirse, sin embargo, que el homicidio calificado es problemático. Después de todo, si la orientación es a la protección de bienes jurídicos individuales y la vida es el bien jurídico de mayor relevancia, no se advierte qué puede expresar mayor necesidad de pena ${ }^{44}$, salvo en los casos de homicidio calificado por utilización de medios generalmente peligrosos ${ }^{45}$ - una de las calificantes del derecho penal alemán. $\mathrm{O}$, mejor: se asume que hay una explicación plausible en la pretensión del sistema de reconocer homicidios "éticamente" más graves o de identificar autores peligrosos, pero la incorporación de consideraciones de esta clase sería incompatible con un derecho penal orientado a la protección de bienes jurídicos ${ }^{46}$.

Pese a su apariencia prevencionista ligada al paradigma de la protección de bienes jurídicos, el argumento sólo tiene sentido de no ser realmente prevencionista. El argumento dice: la vida es el bien jurídico de mayor relevancia para el individuo, por lo que circunstancias ulteriores ligadas al homicidio no pueden aumentar el disvalor de resultado de la conducta. Más allá de la convincente que resulte este modo de argumentación, es obvio que no es prevencionista: preventivamente considerado, la prestación del derecho penal se analiza en relación a la idoneidad en la prevención de otros hechos y, por ello, no puede ser en sí relevante que el hecho particular por el que se condena sea más o menos

y s. Ver también PERALTA, José Milton, "Homicidios por odio como delitos de sometimiento", InDret, 4 (2013), pp. 7 y ss.. Limitado al ensañamiento así también ALONSO ÁLAMO, Mercedes, El ensañamiento, Granada: Editorial Comares, 2015, pp. 56 y ss., 81 y ss.

${ }^{43}$ GONZÁLEZ RUS, "El parricidio. El asesinato", cit. nota nº 5, p. 60; GONZÁLEZ RUS, "Artículos 139140”, cit. nota n 42, pp. 121-57 (p. 125); MORALES PRATS, “Art. 138-140”, cit. nota n 30, p. 48.

${ }^{44}$ Esta es una asunción generalmente presente en la literatura alemana y que, como veremos, tiene relevancia en el tratamiento dogmático del homicidio calificado. Acertado entre nosotros PEÑARANDA RAMOS, Estudios sobre el delito de asesinato, cit. nota $\mathrm{n}^{\circ} 14$, pp. 72 y ss. En Alemania la cuestión es algo distinta, ya que el derecho positivo distingue entre condiciones de apreciación de la peligrosidad (en la institución de la custodia de seguridad) y condiciones de apreciación de pena merecida. Así correctamente KÖHLER, "Zur Abgrenzung des Mordes", cit. nota $n^{\circ} 30$, p. 122; SCHNEIDER, “§ 211", cit. nota $n^{\circ} 37,(\mathrm{Nm} .17)$. Que la distinción pueda ser tan claramente producida entre nosotros en la práctica es algo que puede ser dudado.

${ }^{45}$ Así explícitamente en BACIGALUPO, Estudios sobre la Parte Especial, cit. nota n ${ }^{\circ}$ 5, p. 28 y s.; MORALES PRATS, “Art. 138-140”, cit. nota n 30, pp. 29-31; 43 y s.

${ }^{46}$ GONZÁLEZ RUS, "El parricidio. El asesinato", cit. nota n 5, p. 61; GONZÁLEZ RUS, "Artículos 139140 ", cit. nota n' 42 , p. 127. 
WILENMANN, Javier. "El sistema de graduación de la pena del homicidio en el derecho chileno".

lesivo. El acercamiento en cuestión tiene problemas dogmáticos todavía más serios. Con completa independencia de la inconsecuencia respecto a la asunción de un punto de partida prevencionista original, este modo de acercamiento se muestra como problemático ya que en los hechos no puede evitar convertirse en un instrumento de crítica legislativa. Si bien desde un punto de vista político puede ser deseable pensar en modos distintos de graduación del homicidio, que el discurso dogmático se estructure de este modo no puede sino ser inadecuado.

Algo similar puede decirse de la orientación "retributiva". La demostración del mayor reproche ligado a cada una de las circunstancias tiende a no ser más que argumentación político-moral, a veces más bien ingenua, en otras ocasiones más sofisticada. En su mejor versión, este modo de acercamiento coincide con una reconstrucción de las representaciones culturales o políticas que se ven asociadas a la calificación del homicidio $^{47}$ : ciertos actos serían en sí expresivos de mayor desprecio por normas fundantes de la comunidad que otros, pese a que su resultado bruto sea el mismo. Dar cuenta de los casos en que ello es así y de los fundamentos de la representación ética en cuestión es un aporte valioso. En la producción de dogmática sistemáticamente orientada, este acercamiento tampoco puede ofrecer, sin embargo, soluciones.

La caída en esta especie de dilema insoluble, cuyo resultado es la transformación casi insalvable del estudio dogmático del homicidio calificado en crítica legislativa, parece ser inevitable. En sistemas jurídicos maduros, en que pese a sus deficiencias en la estructuración del discurso, la dogmática recoge siempre los grupos de casos que especifican las condiciones de aplicación de las distintas reglas, esto puede no ser paralizante. Pero en sistemas en ese sentido menos maduro, la imposibilidad de estructurar un discurso sistemáticamente controlable respecto al homicidio calificado implica el mantenimiento de un statu quo dogmático que, en los hechos, lleva de vuelta no sólo al modelo semántico, sino que ante todo a inseguridad respecto a los casos en que el homicidio calificado es aplicable.

Pese a lo poco alentador que resulte el escenario actual en el estudio del homicidio calificado en Chile y en general en el mundo hispanoparlante, ello no siempre fue así. Hallazgos dogmáticos fundamentales, que pasaron a estructurar la dogmática posterior, pueden obtenerse a partir del estudio de los modelos de graduación de la pena (incluyendo el condicionamiento de la pena de muerte/presidio perpetuo) en sistemas jurídicos comparados. La vieja pregunta que se cree superada por la relación entre homicidio simple y calificado $^{48}$ y el modo en que se estructura la calificación del homicidio es, de este modo, crucial en el establecimiento de una dogmática sistemáticamente orientada. En esta sección se trata de la producción de la demostración del valor de una orientación de esta clase.

\footnotetext{
${ }^{47}$ En este sentido, valioso por ejemplo PERALTA, "Homicidios por odio como delitos de sometimiento", cit. nota $\mathrm{n}^{\circ} 42$, pp. 7 y ss.

${ }^{48}$ Entre nosotros brevemente tematizada por BACIGALUPO, Estudios sobre la Parte Especial, cit. nota ${ }^{\circ} 5$, pp. 29, 31 y s.
} 
Polít. crim. Vol. 11, No 22 (Diciembre 2016), Art. 12, pp. 721-765.

[http://www.politicacriminal.cl/Vol_11/n_22/Vol11N22A12.pdf]

\subsection{Los modelos de calificación del homicidio.}

Tanto en perspectiva histórica como comparada, los ordenamientos jurídicos han estructurado de distinta forma la graduación de la pena tratándose de delitos de homicidio doloso. Esta es una tendencia prácticamente universal: la pura distinción entre homicidio imprudente y doloso como graduación típica de la pena es considerada insuficiente por la legislación o, en el derecho pre-moderno, por la práctica judicial, tendiendo en uno u otro caso a incorporar graduaciones de la pena ya en la estructuración de los tipos de homicidio $^{49}$.

Este hecho es asumido, a veces, con cierta perplejidad por la literatura académico-jurídica. Después de todo, en el homicidio doloso se trata siempre de la máxima afectación a los intereses individuales de otro y esa máxima afectación por definición no podría ser graduable. Pero ello sólo demuestra que políticamente considerada, la pura graduación en base al resultado bruto individual es rechazada y que las consideraciones de proporcionalidad se construyen sobre otros factores. La calificación del homicidio expresa esa graduación político-valorativa: a ciertos homicidios se les atribuye legislativamente (lo que, en principio, supone que ello tenga reflejo en el mundo de la cultura) el sentido de expresar mayor desprecio por el derecho a la vida ajena o por otras normas relevantes de la comunidad o, formulado de modo negativo, los sistemas en cuestión asumen que no toda acción de matar a otro dolosamente implica necesariamente desprecio general por la vida de otro. La siguiente descripción de las pretensiones de la calificación del homicidio de Enrique Peñaranda, siguiendo a Michael Köhler ${ }^{50}$, es, a este respecto, esclarecedora:

"La asignación por principio a todo homicidio doloso de las máximas penas podría ser muy eficaz para expresar simbólicamente la fundamental importancia que se le concede al bien jurídico de la vida humana, pero no sería correcta, ni proporcionada, al pasar por alto las distinciones que es necesario hacer para captar el diferente significado que, desde el punto de vista personal como general, puede adquirir la acción de matar en atención a su contexto. ${ }^{51}$ ",

Los modelos de calificación del homicidio son modos de institucionalización de la atribución de ese distinto significado a la acción de matar a otro. De nuevo aquí es posible acercarse con un cierto escepticismo de base: ¿no será esto expresivo de un derecho penal de la actitud interna (Gesinnungsstrafrecht), ya superado, asumir que el homicidio doloso puede tener distintos significados dependiendo del contexto?

Frente a esta pregunta, basta por ahora con dar cuenta de su carácter cultural o político a partir de la contingencia de las atribuciones de significado a hechos brutos: la atribución de significado tiene lugar desde afuera; ella no es el descubrimiento de un significado que los hechos tengan en sí, por lo que la igualdad de resultado bruto no supone igualdad de significado. Ni siquiera el mundo pre-político de la cultura tiene significado en sí, sino que se estructura sobre la base de representaciones no vinculadas (al menos necesariamente) a

\footnotetext{
49 Así también SCHAFFSTEIN, Abhandlungen zur Strafrechtsgeschichte, cit. nota $\mathrm{n}^{\circ}$ 8, p. 103. Entre nosotros correctamente GARRIDO MONTT, El homicidio y sus figuras penales, cit. nota ${ }^{\circ} 2$, p. 135 y s.

${ }^{50}$ Véase KÖHLER, "Zur Abgrenzung des Mordes", cit. nota n 30, p. 121 y s.

${ }^{51}$ PEÑARANDA RAMOS, Estudios sobre el delito de asesinato, cit. nota $\mathrm{n}^{\circ} 14$, p. 77.
} 
WILENMANN, Javier. "El sistema de graduación de la pena del homicidio en el derecho chileno".

fines pero puestas allí por el mundo construido socialmente. Dada la contingencia de la atribución de significados - lo que en un mundo normativo políticamente configurado, esto es, auto-conscientemente configurado, supone una decisión por esa atribución de significado -, la pregunta por su justificación depende de lo que se quiera expresar con ella o lo que ella refleje respecto a las asunciones culturales que la hacen posible. Políticamente considerado, la pregunta es entonces por la conveniencia y legitimación de esa diferenciación en la atribución de significado a partir del reconocimiento de distintas clases de homicidio.

Esta pregunta legitimatoria no es algo en lo que sea necesario detenerse por ahora. Lo que nos interesa es otra cosa, a saber, la revisión de los modos en que se produce esa diferenciación en la atribución de significado en los modelos jurídicos que a grandes rasgos son conocidos, con el objeto de determinar (i) cuáles son las asunciones de base que les son atribuibles; (ii) si marcan con suficiente claridad y precisión esas diferencias; y (iii) cuál es el mejor interpretación que en ese contexto puede dársele al artículo 391 número $1 \mathrm{CP}$.

\subsubsection{El modelo tradicional o de la premeditación.}

El modelo tradicional ${ }^{52}$ de graduación del homicidio doloso en la cultura jurídica europea de influencia romana (incluyendo aquí a la tradición del common law) es el modelo de la premeditación. La distinción entre homicidio simple y calificado a partir de la distinción entre homicidio premeditado y no premeditado se encuentra presente en la regla original, luego deformada en su sentido, de la malice aforethought del common law; en el derecho común alemán (fürsetzliche mutwillige Tötung en la formulación de la Carolina, luego traducido como Vorbedacht y finalmente como Überlegung) ${ }^{53}$; en la doctrina medieval italiana $^{54} \mathrm{y}$, posteriormente, en las codificaciones europeas del siglo XIX empezando con el Code Pénal de $1810^{55}$, e incluyendo las codificaciones españolas de 1848 y 1870 y al CP chileno.

\footnotetext{
52 Designado también como "clásico" por HEINE, "Stand und Entwicklung der Mordtatbestände", cit. nota n 31 , p. 331 y s.

${ }^{53}$ Sobre estos dos puntos véase en detalle SCHAFFSTEIN, Abhandlungen zur Strafrechtsgeschichte, cit. nota $\mathrm{n}^{\circ}$ 8, pp. 104 y ss. Según Schaffstein esta visión debe ser matizada: es usual que en la tradición del derecho común alemán, incluyendo a Carpzov, se razonara en oposición a la Carolina en este punto y se favoreciera un modelo circunstancial de calificación que resultaría más adecuado a la cultura germánica. Pese a ello, lo que es indudable - y, según él, lo único que sería indudable - es que la cultura jurídica europea del siglo XIX recibió la distinción entre homicidio simple (por afecto) y homicidio calificado (premeditado) como si fuera tradicional y estructuró sus distinciones a partir de ella. Durante todo el siglo XIX y hasta el año 1941 habría sido así dominante la comprensión de la distinción homicidio simple y calificado a partir del binomio “premeditación/afecto". Así también SCHNEIDER, "§ 211 ”, cit. nota n 37, (Nm. 2).

${ }^{54}$ Sobre el modo de estructuración de la calificación del homicidio en la doctrina medieval italiana SCHAFFSTEIN, Abhandlungen zur Strafrechtsgeschichte, cit. nota ${ }^{\circ} 8$, pp. 107 y ss. La lectura de Schaffstein implica la calificación del modelo de la premeditación como estructuración unitaria de un modelo de calificación ética (circunstancial) que le precedía.

${ }^{55}$ Véase al respecto GRÜNEWALD, Anette, Das vorsätzliche Tötungsdelikt, Tübingen: Mohr Siebeck, 2010, pp. 58 y ss.
} 
Para juristas formados en la tradición de la dogmática penal en su forma operativa, la distinción es difícil de entender y tiende a ser, de hecho, mal comprendida ${ }^{56}$. La premeditación es vinculada, en algún sentido, al concepto general de dolo y, a partir de la constatación (falsa) de que no puede ser distinguida de éste o de que no debiera serlo, ella es rechazada como criterio operativo o al menos como criterio que merezca reconocimiento legislativo. Esta ha sido, de hecho, en general la actitud de la doctrina penal en Español desde Pacheco ${ }^{57}$ respecto de la premeditación: se asume, en primer lugar, que es un concepto psicológico difícilmente distinguible del dolo - una doble asunción problemática $-{ }^{58}$ luego se afirma, a partir de ello, que es un caso poco relevante o inaplicable de homicidio calificado; y luego se llega a un acuerdo general en que "debe desaparecer"59 o que, en cualquier caso, no tiene aplicación práctica. En España, este proceso se completó con la eliminación (generalmente alabada) ${ }^{60}$ de la premeditación en el Código Penal Español de 1995.

Esta actitud se basa en una incomprensión sistemática del homicidio calificado por premeditación, a saber, la asunción de que el modelo de la premeditación es técnicamente un modelo de distinción entre homicidio simple y homicidio calificado por medio de la constitución del primero en delito básico y del segundo en delito calificado bajo la introducción (mal realizada) de un criterio externo que justifique la calificación.

Bajo esta asunción, la pregunta por la relevancia de la premeditación parece plantearse por sí misma: a menos de que se trate de un homicidio respecto al cual se exija una forma calificada de dolo (típicamente: directo de primer grado), no sería posible reconocer elementos que pueden explicar un aumento de pena en el homicidio calificado que no sean expresivos de un derecho penal de la actitud interna. El argumento se construye, sin embargo, sobre dos asunciones falsas: (i) que la premeditación tiene vínculos directos con el dolo; y (ii) que se trata de un elemento calificante de un simple matar a otro con dolo ${ }^{61}$.

\footnotetext{
${ }^{56}$ Este es casi sin excepciones el caso de la literatura jurídica en español y especialmente chilena. Su tratamiento se agota en pura determinación semántica y fijación de los criterios extraídos en exigencias de "frialdad" o "premeditación cronológica". Así, por ejemplo, GARRIDO MONTT, El homicidio y sus figuras penales, cit. nota $\mathrm{n}^{\circ}$ 2, pp. 145 y ss.; GARRIDO MONTT, Derecho Penal. Tomo III, cit. nota n ${ }^{\circ}$ 3, p. 62 y s.; MATUS/RAMÍREZ, Lecciones de Derecho Penal Chileno, cit. nota n 4, p. 53 y s.; BALMACEDA, Manual de Derecho Penal. Parte Especial, cit. nota ${ }^{\circ} 3$, p. 35 y s. Entre nosotros, el tratamiento probablemente más correcto de la premeditación puede encontrarse en ETCHEBERRY, Derecho Penal. Tomo III, cit. nota $\mathrm{n}^{\circ} 3$, pp. 55 y ss., quien pese a reconocer los problemas del modo de tratamiento extendido en la literatura española, termina adoptando sus conclusiones.

${ }^{57} \mathrm{La}$ actitud crítica, derivada de incomprensión, de la premeditación en la doctrina española puede encontrarse ya en PACHECO, El Código Penal Concordado y Comentado, cit. nota n ${ }^{\circ} 30$, p. 22 y s.

${ }^{58}$ MORALES PRATS, “Art. 138-140”, cit. nota n 30, p. 56. Entre nosotros MATUS/RAMÍREZ, Lecciones de Derecho Penal Chileno, cit. nota ${ }^{\circ} 4$, p. 54 y s.

${ }^{59}$ Ilustrativo, con amplias referencias, GONZÁLEZ RUS, "El parricidio. El asesinato", cit. nota n p. 72 y s.; MORALES PRATS, “Art. 138-140”, cit. nota n 30, p. 56. Entre nosotros GARRIDO MONTT, El homicidio y sus figuras penales, cit. nota $\mathrm{n}^{\circ} 2$, p. 152 y s.; GARRIDO MONTT, Derecho Penal. Tomo III, cit. nota $\mathrm{n}^{\circ} 3$, p. 62; BALMACEDA, Manual de Derecho Penal, cit nota n 3, p. 35 y s.

${ }^{60}$ Este es incluso el caso de PEÑARANDA RAMOS, Estudios sobre el delito de asesinato, cit. nota $\mathrm{n}^{\circ} 14, \mathrm{p}$. 9 con nota 8 .

${ }^{61}$ En algo que resulta curioso, la asunción de ambas premisas no siempre tiene lugar por desconocimiento de la interpretación tradicional del modelo del derecho común. Pese a que en el fondo asuma, con el resto de la literatura en Español, que la premeditación es un elemento difícilmente distinguible del dolo y, por lo mismo,
} 
WILENMANN, Javier. "El sistema de graduación de la pena del homicidio en el derecho chileno".

Ninguna de las dos premisas resiste análisis: en su pretensión conceptual original, la premeditación no tiene vínculos con el dolo, sino que ella opera, en cambio, sobre la base de que tanto los hechos que se subsumen bajo el concepto como aquéllos que no lo hacen son dolosos; ${ }^{62}$ y ella funciona en su mejor versión sobre la base de una reconstrucción de las relaciones entre homicidio simple y homicidio calificado en que los conceptos de premeditación y su negación (el actuar bajo afecto) se implican recíprocamente. Esto es: homicidio calificado se vería constituido por todo matar a otro no sujeto a un arrebato o, lo que parece ser lo mismo, homicidio simple sería todo matar a otro sin premeditación, lo que podría ser expresado con la introducción del elemento adicional, al parece privilegiante, del actuar bajo pasiones, arrebatos y, en general, emociones que tengan potencial explicatorio del hecho (concepto técnico de "afecto").

Considerado desde un punto de vista lógico, si el universo de homicidios dolosos debe estar cubierto por la conjunción del homicidio simple y del homicidio calificado, entonces uno de ellos debe ser tipo básico y el otro tipo calificado. Si ambos tuvieran elementos adicionales a un supuesto de hecho distinto del otro que permita decir a la vez que uno es calificado y el otro privilegiado, entonces debiera existir un tipo básico no criminalizado, con lo que se crearían vacíos absurdos de punibilidad. Ello sugiere la lectura del asesinato como tipo calificado. Sin embargo, la lectura tradicional del modelo de la premeditación tiende a ser efectuada bajo la asunción inversa: se interpreta al homicidio simple como homicidio privilegiado por la presencia del elemento subjetivo externo al dolo, a saber, el actuar bajo un arrebato o "afecto" (si se quiere: con culpabilidad disminuida) y el homicidio calificado es por lo tanto constituido en delito básico al ser tratado como homicidio doloso simplemente no sujeto a un arrebato.

La más sofisticada versión de esta correcta comprensión de la premeditación se encuentra en la crítica de Hugo Hälschner a la declaración de primacía conceptual del afecto (Affekt; tal vez mejor traducido por arrebato o pasión) por sobre la premeditación.

La reconstrucción de Hälschner se entiende sólo en el contexto legislativo en que tenía lugar, a saber, como comentario al aparentemente peculiar $\$ 211$ del Código Penal del Imperio, el que describía al homicidio simple (Totschlag) como aquél que tiene lugar "sin premeditación"63. La formulación en cuestión podía ser criticada por dos razones: como técnica legislativa, la definición de un tipo mediante un elemento negativo ("ausencia de

difícilmente cualificante, BACIGALUPO, Estudios sobre la Parte Especial, cit. nota n 5, pp. 29 y ss., reconoce, por referencia a Feuerbach, que no siempre se la construye como un elemento propiamente calificante del homicidio y que éste asumía que el homicidio simple era más bien privilegiado. Asumiendo, sin embargo, el paso siguiente en el proceso de degradación de la premeditación - que la premeditación ya no es importante -, su análisis se detiene allí. Algo similar tiene lugar en RODRÍGUEZ DEVESA, Jose María y SERRANO GÓMEZ, Alfonso, Derecho Penal Español, Madrid: Dykinson, 1995, p. 46. Rodríguez también podía dar cuenta del rol estructurante de la premeditación en la cultura jurídica alemana y en el Código Penal Francés de 1810 pero lo descartaba por ser "subjetivo", dando cuenta de una estructuración más moderna y pragmática en la legislación española de las "circunstancias" de calificación en la nota 14. Las razones de esta apreciación no son claras.

${ }^{62}$ La desconexión entre dolo y premeditación era reconocido por la literatura incluso anterior al siglo XVIII de acuerdo a SCHAFFSTEIN, Abhandlungen zur Strafrechtsgeschichte, cit. nota n 8, p. 104.

${ }^{63}$ Sobre esta formulación y la relación con su precedente inmediato - el Código Penal Prusiano de 1851 véase ESER, Empfielt es sich, die Straftatbestände des Mordes, cit. nota n 8, pp. 23 y ss. 
Polít. crim. Vol. 11, No 22 (Diciembre 2016), Art. 12, pp. 721-765.

[http://www.politicacriminal.cl/Vol_11/n_22/Vol11N22A12.pdf]

premeditación"; en cualquier caso, se trata de la misma técnica utilizada por el artículo 391 número $2 \mathrm{CP}$ hasta nuestros días) si bien no habría podido ser considerada ilógica, habría sido al menos llamativa por su redundancia. La crítica central era, sin embargo, de fondo. La literatura alemana del siglo XIX había reconstruido el viejo concepto de premeditación tomado del derecho común bajo la asunción de que, en realidad, era un modo negativo de tratar al homicidio simple como un homicidio realizado bajo "afecto" (arrebato, pasión) 64 . La redacción del Código Penal del Imperio sería así, en su mejor versión, coincidente en el fondo con la comprensión legada por la literatura del siglo XIX de la premeditación, la que a su vez empalmaría directamente, como interpretación, con el modelo legado por la doctrina medieval italiana y por el derecho común, pero esa coincidencia la expresaría de un modo innecesariamente ambiguo.

En su crítica, Hälschner no pretendía romper con la idea de fondo que se encontraba detrás de la reconstrucción tradicional: este también asumía que sólo la distinción entre premeditación y su negación (el "afecto") permitiría construir adecuadamente la distinción entre homicidio simple y calificado ${ }^{65}$, pero que el modo correcto de expresión técnica de esta distinción era el utilizado por el Código Penal del Imperio y no la técnica preferida por la literatura desde Feuerbach de simplemente construir un tipo privilegiado de homicidio bajo "afecto".

El argumento de Hälschner se construye sobre un análisis cuyo objeto es demostrar la existencia de una contradicción aparente tanto en la pretensión de calificar mediante el concepto de premeditación como en la pretensión de privilegiar mediante el concepto de actuar bajo "afecto". El argumento es relativamente sencillo: una acción parece no poder ser designada como tal sin algún grado de reflexión (Überlegung en sentido amplio), por lo que la asunción de que existe un homicidio doloso no premeditado sería contradictoria.

"Una completa ausencia de reflexión (Überlegung im weiteren Sinne des Wortes) le privaría al actuar humano del carácter de acción; homicidio doloso sin alguna forma de reflexión es por ello una contradicción en sí misma. Una acción humana no es pensable sin que alguna excitación de la voluntad haga surgir la representación de que debe alcanzarse un fin (...) y sin que esa representación ejerza su influencia motivadora a su vez en la voluntad."

Al mismo tiempo, toda acción humana sería el reflejo de un impulso motivacional y, con ello, se originaría siempre en algún afecto.

"Tradicionalmente se considera al afecto (Affekt) como el momento que excluye la premeditación/reflexión (Überlegung). A este respecto es necesario recordar, que

\footnotetext{
${ }^{64}$ Fundamental en su influencia en el desarrollo posterior FEUERBACH, Paul Johann Anselm, Lehrbuch des gemeinen in Deutschland gültigen peinlichen Rechts, Neudruck 1; Aalen: Scientia Verlag (George Friedrich Heyer's Verlag), 1986, p. 374.

${ }^{65}$ HÄLSCHNER, Hugo, Das gemeine Deutsche Strafrecht. Band II, Nachdruck; Goldbach: Keip Verlag (Adolph Marcus), 1997, p. 35 y s.

${ }^{66}$ HÄLSCHNER, Das gemeine Deutsche Strafrecht, cit. nota n ${ }^{\circ} 65$, p. 36.
} 
WILENMANN, Javier. "El sistema de graduación de la pena del homicidio en el derecho chileno".

actuar sin afectos, sin que la voluntad sea puesta en movimiento por alguna excitación, no es pensable. ${ }^{67 "}$.

La necesariedad tanto de la premeditación como del "afecto" a la acción humana implicaría que todo homicidio doloso debiera calificarse siempre a la vez como originado en un afecto y como premeditado, lo que haría incomprensible el sistema de derecho positivo. Ello daría cuenta de una doble contradicción aparente en la ley: ella asumiría que el homicidio doloso puede ser distinguido del homicidio premeditado y que el homicidio doloso puede ser distinguido del homicidio bajo afecto, en condiciones de que, en tanto acción, todo homicidio doloso debiera ser a la vez premeditado y tener lugar bajo afecto.

La solución a la contradicción expuesta por Hälschner no tiene, por cierto, nada de esotérica y sigue más bien el sentido común: se trata de determinar especificaciones legales de los conceptos de premeditación y de "afecto" que permitan distinguirlos de su uso natural (o hegeliano), bajo el cual toda acción es a la vez premeditada y tiene lugar bajo afecto. Así:

“(s)i bien no es (...) pensable una conducta humana por la que se pueda ser responsable sin que le anteceda esa representación [de fines conforme a los cuales actuar], una acción puede no ser premeditada, sin embargo, en el sentido restringido en el que el lenguaje natural y la ley utilizan el concepto de premeditación (Überlegung). Premeditación, reflexión, requieren no sólo el surgimiento de una representación que motive a actuar a partir de una excitación de la voluntad, sino que también que otros fines posibles sean comparados en su valor y en las diferencias de su contenido; más allá de esto que una acción no sea considerada sólo como medio que sirva a la consecución de un fin y con ello a la consecución de un resultado, sino que también el medio sea comparado con otros en su capacidad de realizar el fin; y, finalmente, que la acción sea analizada no sólo en su valor subjetivo, sino también en su valor objetivo en relación con el cumplimiento de obligaciones. Que acciones no reflexionadas en este sentido pueden tener lugar, es algo que nos enseña la experiencia, y la mayor parte de las acciones son de hecho no premeditadas, ya que nuestra experiencia de vida nos lleva a responder a ciertos incentivos antes experimentados de inmediatos con la necesidad de realizar un fin. ${ }^{68,}$.

También el concepto de "afecto" podría ser probablemente especificado de un modo tal que no sea inmanente a toda acción humana. Si uno se preguntara, sin embargo, por la clase de afectos que justificarían que la ley califique una acción homicida como homicidio simple y no calificado, la respuesta sería seguramente: debiera tratarse de aquellos afectos que excluyen la reflexión/premeditación (Überlegung) en sentido restringido, porque el actuar contra el derecho tras una reflexión sería expresivo de una contrariedad cualitativamente más intensa a este ${ }^{69}$. Si esto es así, entonces la definición del homicidio simple con el elemento negativo "no premeditado" (a causa de un afecto) y no, en cambio, a partir del concepto positivo de "actuar bajo afecto" sería técnicamente adecuada:

\footnotetext{
${ }^{67}$ HÄLSCHNER, Das gemeine Deutsche Strafrecht, cit. nota ${ }^{\circ} 65$, p. 37 .

${ }^{68}$ HÄLSCHNER, Das gemeine Deutsche Strafrecht, cit. nota n ${ }^{\circ} 65$, p. 36 y s.

${ }^{69}$ Similar KÖHLER, “Zur Abgrenzung des Mordes”, cit. nota ${ }^{\circ}$ 30, pp. 133 y ss.
} 
"El concepto [legal] de actuar bajo afecto sólo puede designar, con ello, una excitación tan fuerte de la voluntad que excluya la posibilidad de la reflexión en sentido estricto. (...) Lo decisivo de una acción no premeditada no es, por ello, la falta de afecto, ya que toda acción tiene como presupuesto algún afecto, sino la falta de reflexión ligada a un afecto, por lo que es en sí correcto que la legislación designe al homicidio simple (Totschlag) como homicidio (Tötung) sin premeditación y no, en cambio, como homicidio realizado con afecto. ${ }^{70,}$.

Esto es el modelo de la premeditación construido por la cultura jurídica europea y que subyace al modelo tradicional correctamente entendido. Éste asume que dada la enorme intensidad de las penas del homicidio - en Alemania, originalmente: la muerte por la rueda; luego: la pena de muerte -, es conveniente identificar casos que no sean expresivos en sí de desprecio por la prohibición del homicidio pese a tratarse de homicidios dolosos. El modelo de la premeditación no es ni siquiera en la versión defendida por Hälschner, por ello, un verdadero modelo de la calificación, sino que es un modelo del privilegio. La tendencia de crítica legislativa de sugerir la estructuración de un modelo de privilegio que revisaremos a continuación debe entenderse, por ello, como una pretensión de vuelta al modelo tradicional con alteración de los aspectos problemáticos dados por la disponibilidad de un solo criterio de delimitación ${ }^{71}$.

\subsubsection{El modelo del privilegio.}

Desde hace algunos años, pero con particular intensidad a partir de la formación de una comisión de revisión de los delitos de homicidio en el año 2014-2015 ${ }^{72}$, la literatura alemana ha discutido extensamente sobre el mejor modelo legislativo de graduación de la pena en el homicidio ${ }^{73}$. Esta permanente conciencia de necesidad de reforma ciertamente se basa en parte en el origen de la actual versión del $\S 211$ StGB en una reforma del año y en su peculiar lenguaje, el que no define un hecho punible sino que una clase de autor ("es asesino quién...") basado en la doctrina penal nacionalsocialista de que el derecho penal

\footnotetext{
${ }^{70}$ HÄLSCHNER, Das gemeine Deutsche Strafrecht, cit. nota ${ }^{\circ}$ 65, p. 37 y s.

${ }^{71}$ Pese a lo anterior, los partidarios del modelo del privilegio tienden a explicitar que no proponen una vuelta atrás en esta dirección. Así KUBICIEL, Michael, "Mord als Grundtatbestand? Ein Vorschlag zur Neukonzeptualisierung der $\S \S 211,212$ StGB”, en: BOCKEMÜHL, Jan et al. (Eds.), Festschrift für Bernd von Heintschel-Heinegg zum 70. Geburtstag; München: Beck, 2015, pp. 267-74 (pp. 268 y ss.) o GRÜNEWALD, Das vorsätzliche Tötungsdelikt, cit. nota $\mathrm{n}^{\circ}$ 55, pp. 69 y ss. ESER, Albin y STERNBERGLIEBEN, Detlev, "Vorbemerkungen zu den $\S \S 211 \mathrm{ff.",} \mathrm{en:} \mathrm{ESER,} \mathrm{Albin} \mathrm{(Ed.),} \mathrm{Schönke/Schröder}$ Strafgesetzbuch Kommentar, 29a ed., München: C.H. Beck, 2014, pp. 1996-2031 (Nm. 4), asumen que sus propuestas tienen diferencias con la premeditación, por partir ésta de un concepto psicológico. Pero esto es sólo una asunción de una interpretación poco convincente de la premeditación: en su mejor versión, se trata a su vez de una graduación de la pena por contexto y atribución de sentido a partir de éste. Problemático es, más bien, su falta de ductilidad en la posibilidad de captar circunstancias de privilegio que no se dejen designar como afectos o, al revés, en su capacidad de discriminar "afectos que niegan la capacidad juicio", en la nomenclatura de Hälschner, respecto a los cuales no se reconozca el privilegio. Este es el caso tanto de homicidios premeditados en situación de desesperación (homicidio del marido maltratador) como de homicidios realizados "por piedad". Sobre las críticas al modelo de la premeditación en la literatura del Imperio Alemán y de la República de Weimar, véase Eser, p. 28s.

72 A este respecto véase sólo GRÜNEWALD, Anette, Reform der Tötungsdelikte, Tübingen: Mohr Siebeck, 2016 , p. 1 ff.

${ }^{73}$ Véase HEINE, "Stand und Entwicklung der Mordtatbestände”, cit. nota n 31, pp. 315-52 (pp. 315 y ss.); GRÜNEWALD, Das vorsätzliche Tötungsdelikt, cit. nota ${ }^{\circ} 55$, pp. 1 y ss., con exhaustivas referencias.
} 
WILENMANN, Javier. "El sistema de graduación de la pena del homicidio en el derecho chileno".

debe servir al reconocimiento de clases de personas. Pero al menos en el mundo académico y jurisprudencial, la razón central de la constante discusión sobre reforma al § 211 StGB ha sido la constatación de defectos valorativos en su estructuración y no, en cambio, el problema simbólico de la redacción. Pese a que el problema central a este respecto se ve vinculado a la falta de alternativas al presidio perpetuo en el $\S 211 \mathrm{StGB}$, la técnica de construcción de la relación con el homicidio simple también es intensamente discutida.

A pesar de no tratarse del modelo en definitiva apoyado por la comisión, la que ha sugerido más bien una revisión particulares de las circunstancias de calificación del actual $\S 211$ StGB, manteniendo de este modo un "modelo ético", un modelo extensamente defendido en la literatura puede ser denominado modelo del privilegio (o modelo "de dos estadios"), cuya formulación explícita original se debe a Albin Eser ${ }^{74}$, siendo luego tomado como base en el denominado proyecto alternativo de protección de la vida (Alternativer Entwurf Leben $)^{75}$ y que en los últimos años ha sido defendido de un modo especialmente intenso por Anette Grünewald ${ }^{76}$.

El modelo negativo o del privilegio parte de un hallazgo sencillo: no hay nada que parezca justificar que el homicidio doloso, en tanto privación intencional del bien jurídico condicionante de todos los demás, no prevea de entrada al menos la posibilidad de aplicación la mayor pena del sistema (prevista al menos respecto de delitos políticamente comunes), sobre todo cuando no hay pena de muerte ni presidio perpetuo ${ }^{77}$. De la denominada "imponderabilidad de la vida humana" se deduciría esta consecuencia ${ }^{78}$. Sin embargo, sí sería posible apreciar casos en los que el injusto del hecho es menos grave y, con ello, en los que la pena a aplicar debiera ser menor, excluyendo de este modo la aplicabilidad del presidio perpetuo. La legislación debiera así identificar más bien casos en que se justifique la aplicación de penas menos graves, incluso mucho menos graves, que en

\footnotetext{
${ }^{74}$ Eser, p. 106ss. Véase también ESER/STERNBERG-LIEBEN, “Vorbemerkungen zu den $\S \S 211 \mathrm{ff} . ”$ cit. nota $\mathrm{n}^{\circ} 71$ (Nm. 2).

${ }^{75}$ HEINE et al., "Alternativ-Entwurf Leben (AE-Leben)", cit. nota n 29, p. 200 y s., 204 y s., pp. 212 y ss. El AE-Leben no construye, sin embargo, un modelo puramente negativo, ya que la decisión de mantenimiento de la posibilidad de aplicación de prisión perpetua implicó la inclusión de una regulación de condiciones positivas de procedencia de ésta en el inciso segundo del $\S 211$ StGB propuesto. Con ello, pese a su intención, termina siendo un modelo de tres grados.

${ }^{76}$ GRÜNEWALD, Das vorsätzliche Tötungsdelikt, cit. nota n ${ }^{\circ}$ 55, pp. 368 y ss.; GRÜNEWALD, Reform der Tötungsdelikte, cit. nota $\mathrm{n}^{\circ} 72$, pp. 39 y ss. Es importante tener en cuenta, sin embargo, que a diferencia de Eser, Grünewald asume que el único modo a la vez consistente y justificable de estructurar el privilegio es estableciendo un criterio centrado en la responsabilidad por el hecho - el homicidio debiera ser privilegiado siempre que el autor también sea competente por el contexto en el que se explica el hecho. Véase también MÜSSIG, Bernd, "Zur notwendingen Differenzierung von Mord und Totschlag”, en: STUCKENBERG, CarlFriedrich y GÄRDITZ, Klaus Ferdinand (Eds.), Festschrift für Hans-Ulrich Paeffgen zum 70. Geburtstag; Berlin: Duncker \& Humblot, 2015, pp. 301-16 (pp. 312 y ss.); KUBICIEL, "Mord als Grundtatbestand?", cit. nota $\mathrm{n}^{\circ} 71$, p. 273 y s. Entre nosotros, este modelo ha sido defendido por PEÑARANDA RAMOS, Estudios sobre el delito de asesinato, cit. nota $\mathrm{n}^{\circ} 14$, pp. 284 y ss., de acuerdo a quien se trata del único modelo que expresa correctamente aquello que pretende hacer la graduación del homicidio doloso.

77 ESER, Empfielt es sich, die Straftatbestände des Mordes, cit. nota ${ }^{\circ}$ 8, pp. 37 y ss.; HEINE et al., "Alternativ-Entwurf Leben (AE-Leben)", cit. nota n² 29, p. 196.

${ }^{78}$ Críticos de este argumento (con razón) SCHNEIDER, Hartmut, "Vor $\$ \S 211 \mathrm{ff.",} \mathrm{en:} \mathrm{ed.} \mathrm{JOECKS,}$ Wolfgang y MIEBACH, Klaus (Eds.), Münchener Kommentar Strafgesetzbuch Band 4, $2^{\mathrm{a}}$ ed.; München: C.H. Beck, 2012; pp. 360-466 (Nm. 193).
} 
Polít. crim. Vol. 11, № 22 (Diciembre 2016), Art. 12, pp. 721-765.

[http://www.politicacriminal.cl/Vol_11/n_22/Vol11N22A12.pdf]

el homicidio doloso normal, como sucede en el paradigma del homicidio del marido maltratador o como podría suceder en los casos de homicidio por piedad ${ }^{79}$.

Más allá del desacierto en la asunción política inicial, a saber, que en un modelo que asume la imponderabilidad de la vida, la legislación deba asumir la aplicabilidad de la pena máxima al homicidio doloso - esto no tiene por qué ser así -, sus asunciones técnicas son convincentes: continuando y rompiendo con el modelo tradicional de la premeditación es posible obtener una graduación adecuada de la gravedad de los homicidios dolosos. El modelo presenta así continuidad en sus pretensiones respecto del modelo de la premeditación. Al igual que dicho modelo, su pretensión es estructurar la relación entre homicidio simple y homicidio calificado a partir del reconocimiento de uno (Grünewald) o varios (Eser) factores que permitan reconocer que, en ciertos casos, el homicidio doloso no es puro desprecio por la vida de otros. Su diferencia con el modelo de la premeditación se enmarca dentro de ese paradigma: mientras el modelo tradicional confía en la capacidad del binomio premeditación/afecto para marcar siempre esa diferencia, el modelo del privilegio se define exclusivamente por la relación sistemática entre homicidio simple y calificado; sería tarea de la legislación determinar las condiciones bajo las cuales un homicidio doloso es visto como menos grave. A diferencia del modelo de la premeditación, por ejemplo, un modelo como el de Eser permitiría así graduar casos de provocación en que se justifique el privilegio y otros que no; reconocer motivos puramente éticos de privilegio; etc ${ }^{80}$.

Una decisión de estructuración de esta clase se encuentra a su vez en la base del sistema de graduación de las penas del homicidio doloso en el Model Penal Code. A causa de las complicaciones ligadas tanto al lenguaje original del common law (concepto de malice aforethought) como a la complejidad que ha adquirido la graduación en grados del asesinato, el Model Penal Code sugiere abandonar el modelo de Pennsylvania, pese a, en el fondo, estructurar un sistema similar ${ }^{81}$. Así, el $\S 210.2$ (1) define el murder como todo homicidio (doloso) ejecutado con conocimiento o intención o (2) con recklesness expresiva de extrema indiferencia con la vida humana. El manslaughter del $\S 210.3$ se ve constituido, de este modo, por homicidios ejecutados con recklesness o con dolo y con la presencia de algún elemento privilegiante que justifique una atenuación de la pena. El homicidio doloso básico es, en este sentido, el murder; el manslaughter es un tipo privilegiado por razones de imputación subjetiva que no impliquen el paso al homicidio imprudente o por razones éticas que impliquen atenuación de la pena. Este modo de tratamiento deja abierto, sin embargo, el problema original respecto al cual se construyó el modelo de Pennsylvania y, siguiéndolo, la mayor parte de las legislaciones sobre murder en los Estados Unidos: la pena de muerte. El Model Penal Code sugiere, en cambio, tener una regulación diferenciada, que incluya tanto consideraciones procesales como sustantivas, sobre las condiciones de aplicación de la pena de muerte en casos de murder, incluidas en su $§ 210.6$.

\footnotetext{
${ }^{79}$ Sobre la base de este caso se estructuran buena parte de las reflexiones de GRÜNEWALD, Das vorsätzliche Tötungsdelikt, cit. nota $\mathrm{n}^{\circ} 55$, pp. 22 y ss., 278 y ss., 383 y ss.

${ }^{80}$ Véase GRÜNEWALD, Das vorsätzliche Tötungsdelikt, cit. nota ${ }^{\circ} 55$, pp. 69 y ss.

${ }^{81}$ En todo AMERICAN LAW INSTITUTE, Model Penal Code, cit. nota n ${ }^{\circ} 17$, pp. 19 y ss.
} 
WILENMANN, Javier. "El sistema de graduación de la pena del homicidio en el derecho chileno".

\subsubsection{El modelo ético o de circunstancias.}

El modelo ético (así designado generalmente en Alemania) o de las circunstancias es la exacta negación técnica del modelo de la premeditación. Contra la construcción del homicidio calificado como tipo básico, el modelo de las circunstancias asume que la estructuración entre homicidio calificado y homicidio simple debe tener lugar por medio de la construcción del segundo como tipo básico, ya que el homicidio calificado debe poder expresar un juicio ético de ulterior reproche sobre el homicidio doloso ${ }^{82}$. A su vez, contra la pretensión unitaria del modelo de la premeditación, éste asume que sólo una identificación de distintas razones de calificación puede ser adecuada al propósito de graduar la pena del homicidio $^{83}$. Es decir, mientras el modelo tradicional se estructura sobre la construcción del homicidio calificado como tipo básico (i) y asume un criterio unitario de diferenciación con el homicidio simple (ii), el modelo de las circunstancias asume que (i) el homicidio simple debe ser el tipo básico y (ii) que no hay criterio unitario satisfactorio de calificación, por lo que es necesario regular una multiplicidad de calificantes.

Si el modelo tradicional puede ser considerado hegemónico durante la codificación del siglo XIX, el modelo de las circunstancias parece serlo desde el siglo XX. Pese a la elegancia y sencillez del modelo tradicional, la legislación moderna ha tendido a abandonar este modelo y reemplazarlo por el modelo ético (o "circunstanciado"). Esto puede ser apreciado de modo especialmente sencillo en Alemania, Italia o Francia. En Alemania, el sistema pasó de un modelo puro tradicional (sólo el homicidio premeditado es calificado) a un modelo ético también puro (en el sentido de no contener ningún criterio general de delimitación) en el año 1941. En Italia y en Francia, en cambio, la legislación mantuvo la premeditación como calificación, pero ha agregado un sinnúmero de circunstancias calificantes. Algo similar ha tenido lugar en la evolución del concepto de asesinato de primer grado en los Estados Unidos.

La razón de este abandono o complementación progresiva del modelo tradicional se encuentra en buena medida en su incomprensión, pero hay una explicación adicional que es importante tener en cuenta: el modelo ético es mucho más dúctil y, por lo mismo, resulta especialmente seductor para un legislador penal al que le interese expresar preocupación por sensibilidades actuales. Así, por ejemplo, si el homicidio por razones discriminatorias se convierte en un tema políticamente relevante, el modelo ético permite expresar la toma en consideración de esa preocupación simplemente agregando una circunstancia de calificación. Lo mismo sucede en toda clase de preocupaciones, que van desde los homicidios de menores a los homicidios de agentes de policía o de políticos. Como además

\footnotetext{
${ }^{82}$ Esta es la opinión absolutamente dominante en la reconstrucción actual de las relaciones entre Mord y Totschlag en Alemania. Así SCHNEIDER, "Vor $\S \S 211 \mathrm{ff.",} \mathrm{cit.} \mathrm{nota} \mathrm{n} \mathrm{78,} \mathrm{pp.} \mathrm{360-466} \mathrm{(Nm.} 183,185$ y ss.); NEUMANN, "Vor $\S 211 "$, cit. nota $\mathrm{n}^{\circ} 36$ (Nm. 154 y ss.); ESER/STERNBERG-LIEBEN "Vorbemerkungen zu den $\S \S 211 \mathrm{ff} . "$, cit. nota n 71 (Nm. 3 y s.); ESER/STERNBERG-LIEBEN, "§ 211", cit. nota $\mathrm{n}^{\circ} 39$ (Nm. 1); WESSELS/HETTINGER, Strafrecht Besonderer Teil 1, cit. nota n $38, \S 2 \mathrm{Nm}$. $69 \mathrm{y}$ S.

${ }^{83}$ Sobre su origen histórico SCHAFFSTEIN, Abhandlungen zur Strafrechtsgeschichte, cit. nota $n^{\circ} 8, \mathrm{pp} .107$ y ss. Sobre el contexto de reinserción de este modelo en el derecho penal alemán KUBICIEL, "Mord als Grundtatbestand?", cit. nota n ${ }^{\circ}$ 71, pp. 269 y ss.; GRÜNEWALD, Das vorsätzliche Tötungsdelikt, cit. nota ${ }^{\circ}$ 55 , pp. 40 y ss.
} 
Polít. crim. Vol. 11, No 22 (Diciembre 2016), Art. 12, pp. 721-765.

[http://www.politicacriminal.cl/Vol_11/n_22/Vol11N22A12.pdf]

la distinción entre homicidio simple y calificado se ha vuelto menos sensible a partir de la abolición de la pena de muerte, el éxito del modelo ético puede ser explicado en esa ductilidad política. Un legislador preocupado de mantener la pureza del modelo tradicional, a través de la utilización de un solo criterio de demarcación, por definición no puede hacer esto, mientras que un legislador que establezca un modelo de privilegio sólo puede expresar desvaloraciones especiales por la vía indirecta de impedir la aplicación del privilegio en ciertas circunstancias. El modelo ético es, analizado desde una pretensión expresivolegislativa, mucho más dúctil. Esta ductilidad exige, sin embargo, el pago de un precio que al político no le resulta especialmente costoso, pero que es central para el aplicador del derecho: precisamente a partir de la ausencia de realización de un criterio único de distinción y de la mayor ductilidad legislativa, el tratamiento sistemático de este modelo es mucho más complejo.

Que sea más complejo no quiere decir, sin embargo, que no sea posible reconocer criterios de sistematización. Pese a la dispersión de circunstancias calificantes que caracterizan al modelo ético, es posible reconocer razones estructurales generales que pueden explicar el carácter más reprochable de un caso de homicidio. Así, por ejemplo, el Código Penal Alemán y el Código Penal Suizo se estructuran explícitamente a partir de dos grandes criterios de sistematización ${ }^{84}$ : el homicidio puede ser especialmente grave por ser expresivo de motivos especialmente reprochables; o éste puede ser ejecutado de un modo especialmente reprochable, es decir, la calificación ética puede afectar al motivo atribuible al hecho o al modo de realización del hecho.

\subsubsection{La calificación concursal (felony murder) y de identidad (parricidio-femicidio).}

Tanto el derecho comparado como la experiencia histórica muestran que existen consideraciones desligadas del medio comisivo o del motivo de comisión que tienden a ser utilizadas para calificar la pena. Las más relevantes de ellas se refieren a la relación existente entre autor y víctima; el parricidio ha sido probablemente la circunstancia históricamente más relevante de calificación del homicidio. También la comisión del homicidio en relación con otro delito tiende a ser utilizada como motivo de tratamiento de un hecho como homicidio calificado (en sentido amplio). Por supuesto, a diferencia de los demás casos, no hay necesidad técnica en estos casos de entregar un tratamiento especial al homicidio cometido a propósito de la realización de otro delito, ya que en principio, las reglas de determinación de la pena en caso de concurso tienen por objeto graduar el injusto y, a partir de éste, la pena aplicable en situaciones de esta clase. Que los sistemas jurídicos puedan hasta el día de hoy contener reglas de esta clase - este es el caso del secuestro (141 inciso $5 \mathrm{CP}$ ), violación $(374 \mathrm{CP})$ y robo con homicidio $\left(433 \mathrm{~N}^{\circ} 1 \mathrm{CP}\right)$ en el derecho chileno, pero también se encuentra previsto por la regla del felony murder en el derecho de los Estados Unidos o en la violación ( $§ 178 \mathrm{StGB}$ ) y en el robo con resultado de muerte ( $\S$ 251 StGB) del derecho penal alemán- se explica ante todo por razones históricas: se trataba de casos tradicionales a los que se podía aplicar la pena de muerte. Esto es obvio hoy en día

\footnotetext{
${ }^{84} \mathrm{Al}$ respecto véase NEUMANN, Ulfried, "§ 211”, en: KINDHÄUSER, Urs; NEUMANN, Ulfried, y PAEFFGEN, Hans-Ullrich (Eds.), Nomos Kommentar Strafgesetzbuch, $4^{\text {a }}$ ed.; Baden-Baden: Nomos, 2013, pp. 1583-1632 (Nm. 4 y ss.); ESER/STERNBERG-LIEBEN, “\$ 211”, cit. nota n 39 (Nm. 5 y ss.); SAFFERLING, “\$211”, cit. nota n 39 (Nm. 6 y ss.).
} 
WILENMANN, Javier. "El sistema de graduación de la pena del homicidio en el derecho chileno".

en el derecho de los Estados Unidos: la regla del felony murder presenta por cierto componentes de responsabilidad vicaria que hacen que tenga interés de discusión autónomo, pero ella existe y se discute ante todo por sus relaciones con la pena de muerte.

\subsubsection{El problema de los modelos mixtos.}

Con relativa independencia del mantenimiento en la calificación del parricidio y de la inclusión de reglas especiales de determinación de la pena en caso de la realización de homicidio a propósito de otro delito, los sistemas jurídicos vigentes tienden a no incorporar un modelo puro (ético vs. tradicional) en la calificación del homicidio. Modelos puramente éticos pueden encontrarse, al menos en apariencia, en Alemania ${ }^{85}$ - más allá de las calificaciones concursales - y en Suiza, mientras que un modelo puramente tradicional se encuentra consagrado en Austria. En el resto de los ordenamientos que hemos analizado, incluyendo el chileno, la categoría tradicional de distinción de la premeditación se mezcla con la utilización de otras circunstancias calificantes. Esto ha sido llevado al extremo en Francia y en Italia, en donde los respectivos códigos penales contienen una enorme cantidad de circunstancias que califican al homicidio pese a mantener la regla de la premeditación.

Este fenómeno tampoco es difícil de explicar: con la derogación de la pena de muerte, el costo político de la inclusión de circunstancias nuevas de calificación del homicidio es prácticamente nulo, mientras que asumido que sea que la población general seguramente preferirá el mantenimiento de las penas más altas posibles en casos de delitos graves, la derogación de una circunstancia, incluyendo a la premeditación, sí puede tener un costo político. Esto no era así antes de la derogación de la pena de muerte: la introducción de una circunstancia llevaba consigo el riesgo político de que una muerte fuera atribuida a un sector político y el mantenimiento de una circunstancia tan amplia de calificación como la premeditación podía ser también resentido por la población. Sin pena de muerte, la alternativa es simplemente más o menos pena, y es probable que en delitos de asesinato la elección "más pena" no sea especialmente resistida por la población.

Pero la ausencia de costo político no implica ausencia de daño sistemático. La premeditación es un concepto desarrollado y construido con el objeto de actuar como criterio general (incluso: único) de distinción ente homicidio simple y calificado. Su combinación con circunstancias particulares de calificación es, por ello, difícil de reconstruir sistemáticamente. Esto sucede ante todo en sistemas jurídicos con poca conciencia histórica: el peso pragmático de la existencia de una enorme cantidad de circunstancias se siente en la pérdida de relevancia de la premeditación, la que intenta ser reconstruida como circunstancia especial de calificación asimilable a las otras y, a causa de las dificultades ligadas a ello, termina siendo declarada un error legislativo. Esto es, como

\footnotetext{
${ }^{85}$ La calificación "en apariencia" se efectúa aquí en relación con Alemania: desde los fines de los 70 es posible observar una tendencia jurisprudencial de "renacimiento" de la premeditación. Esta tendencia se vincula con la exigencia de adecuación de proporcionalidad individual del BVerfGE. Con el objeto de cumplir con esta exigencia, uno de los modos de acción del BGH en la apreciación de las dos causales más conflictivas (intención de ocultar la realización de un delito y alevosía) ha sido verificar que en los casos en cuestión haya premeditación. Así, por ejemplo, en BGHSt 27, 346. Al respecto, mostrándose de acuerdo con este criterio, KÖHLER, "Zur Abgrenzung des Mordes", cit. nota n 30, pp. 130 y ss.
} 
Polít. crim. Vol. 11, No 22 (Diciembre 2016), Art. 12, pp. 721-765.

[http://www.politicacriminal.cl/Vol_11/n_22/Vol11N22A12.pdf]

hemos visto, el caso de la tradición hispánica: desde Pacheco siempre tendió a desconocerse la función sistemática general de la premeditación, pasando a expresar incomodidad con ella y siendo derogada pese a no haber sido comprendida.

Por supuesto, el modo en que la existencia simultánea de la calificación por premeditación y la premeditación por otras causales puede ser resuelto depende de la configuración particular de cada sistema. No nos interesa, por ello, ver cómo ello puede ser solucionado de un modo general, sino más bien cómo puede serlo en el caso particular de la legislación que ahora estamos en condiciones de calificar como un modelo mixto: la regulación del Código Penal Chileno. De lo que se trata en la última parte de este artículo es producir esta reconstrucción.

\section{El homicidio calificado en el modelo chileno.}

\subsection{Reconstrucción general.}

Visto como concepto general en la determinación de la procedencia de la pena de muerte por delitos comunes, el homicidio calificado chileno se construyó desde el texto original del $\mathrm{CP}$ como un modelo mixto relativamente tradicional, al que uno podría denominar también "italiano" (casi puro), ya que prácticamente todos los casos recogidos en la codificación chilena - tomada con pocas variaciones del Código Penal Español de $1848^{86}$ - se corresponden con las reglas de calificación de la doctrina medieval italiana. Así, en su texto original la pena de muerte se encontraba prevista para el parricidio (artículo $390 \mathrm{CP}$ ) ${ }^{87}$, el homicidio alevoso (una regla históricamente ligada a las costumbres de los pueblos germánicos pero reconocida por la doctrina medieval italiana ${ }^{88}$; el homicidio remunerado (una regla reconocida por la doctrina italiana a causa de la costumbre de ordenar asesinatos) ${ }^{89}$; el envenenamiento (una regla que puede ser encontrada incluso en el derecho penal romano y, por ello, también por la doctrina medieval) ${ }^{90}$; el homicidio con ensañamiento; la regla general de la premeditación ${ }^{91}$; además de una calificación concursal tradicional en casos de robo con homicidio (artículo 433 número $1 \mathrm{CP}$ ) ${ }^{92}$. Posteriormente también los artículos 141 inciso quinto $\mathrm{CP}$, secuestro con homicidio, y 372 bis $\mathrm{CP}$, violación y otros delitos sexuales con homicidio, ampliaron la aplicabilidad de la pena de muerte en estos casos de "calificación concursal".

Pese a que con la derogación de la pena de muerte la necesidad de construcción de un concepto amplio de homicidio calificado, como todo homicidio al que pueda aplicarse la

\footnotetext{
${ }^{86}$ Las dos modificaciones más relevantes respecto al Código Penal Español de 1848 son la eliminación de los medios de peligro común (incendio e inundación) como circunstancia calificante junto al envenenamiento, y la re-introducción de la previsión absoluta de la pena de muerte en el parricidio, desapareciendo con ello la necesidad de contar con un tipo de parricidio calificado respecto al cual procediera en forma absoluta la pena de muerte.

${ }^{87}$ Sobre su reconocimiento en el doctrina medieval italiana Schaffstein, p. 108.

${ }^{88}$ SCHAFFSTEIN, Abhandlungen zur Strafrechtsgeschichte, cit. nota ${ }^{\circ}$ 8, p. 108.

${ }^{89}$ Véase SCHAFFSTEIN, Abhandlungen zur Strafrechtsgeschichte, cit. nota ${ }^{\circ} 8$, p. 107.

90 SCHAFFSTEIN, Abhandlungen zur Strafrechtsgeschichte, cit. nota $\mathrm{n}^{\circ}$ 8, p. 108.

${ }^{91}$ Véase SCHAFFSTEIN, Abhandlungen zur Strafrechtsgeschichte, cit. nota ${ }^{\circ}$ 8, p. 109.

92 Sobre su recepción en la doctrina medieval italiana SCHAFFSTEIN, Abhandlungen zur Strafrechtsgeschichte, cit. nota $\mathrm{n}^{\circ}$ 8, p. 107.
} 
WILENMANN, Javier. "El sistema de graduación de la pena del homicidio en el derecho chileno".

pena de muerte, haya perdido relevancia, ella sigue teniendo valor dogmático en el $\mathrm{CP}$, ya que todavía es posible reunir en esta categoría todos los delitos comunes respecto a los cuales procede el presidio perpetuo. La única excepción (aparente) a esta consideración viene dada por la posibilidad formal de aplicar el presidio perpetuo en casos de secuestro con violación o lesiones gravísimas (141 inciso quinto $\mathrm{CP}$ ) y de robo con lesiones gravísimas (433 número $1 \mathrm{CP}$ ); allí se reconocen casos en que procede formalmente presidio perpetuo sin que haya condena por homicidio.

La aplicabilidad en estos casos del presidio perpetuo fuera de los casos de homicidio calificado en sentido amplio debe ser, sin embargo, descartada. La razón de este descarte se encuentra en la comparación de los marcos penales respectivos con el artículo 372bis CP, el que prevé exclusivamente la aplicabilidad de presidio perpetuo, simple o calificado, para la violación con homicidio. Así, mientras el artículo 372bis CP no incluye ninguna relación concursal que no sea con el homicidio y prevé la procedencia del presidio perpetuo en términos absolutos, los artículos 141 inciso quinto $\mathrm{CP}$ y 433 número $1 \mathrm{CP}$ prevén varias relaciones concursales (no sólo robo con homicidio, también robo con lesiones gravísimas, etc.) pero no así la procedencia absoluta de la pena de presidio perpetuo, sino que configuran un marco más amplio. La única interpretación sistemáticamente consistente, en el sentido de que pueda atribuirse respeto por consideraciones internas de proporcionalidad, consiste en declarar que el rango menor de la pena, no constitutivo de presidio perpetuo, se encuentra previsto justamente para los casos en que no hay homicidio. Es decir: el secuestro con lesiones gravísimas o violación debiera ser castigable sólo con presidio mayor en su grado máximo, mientras que el robo con lesiones gravísimas o violación debiera ser castigable sólo con presidio mayor en su grado medio a máximo. La contracara de esta interpretación pro reo de los artículos 141 inciso quinto $\mathrm{CP}$ y 433 número $1 \mathrm{CP}$ en supuestos no constitutivos de homicidio, es su interpretación contra reo en los supuestos en que sí hay homicidio. La única interpretación sistemáticamente consistente de los marcos penales correspondientes en esos casos es construir un marco (judicial) similar al marco legal del artículo 372 bis CP, esto es, considerar en principio aplicable el presidio perpetuo.

Si esto es así, entonces en Chile sigue existiendo una categoría ampliada de homicidio calificado conformada por (i) parricidio y femicidio; (ii) homicidio calificado por circunstancias distintas de la premeditación; (iii) homicidio calificado por premeditación; (iv) homicidio calificado concursal (robo con homicidio, violación con homicidio y secuestro con homicidio). Los casos (i) y (iv) tienen un tratamiento independiente, pese a que algunos aspectos de las reglas de la determinación de la pena les pueden afectar. A su respecto no se plantean problemas de delimitación típica que sean diferenciables de las preguntas de determinación de la pena. El aspecto central en la reconstrucción típica del modelo chileno es, por ello, la determinación de la mejor interpretación que puede hacerse de la concurrencia de un criterio de distinción general (la premeditación) con criterios de distinción específicos (las demás circunstancias).

\subsection{El homicidio calificado como delito básico en el CP.}

Como en general ha tenido lugar en la tradición hispánica, la interpretación de la premeditación como una calificante particular ha hecho que ella sea tratada de modo 
Polít. crim. Vol. 11, No 22 (Diciembre 2016), Art. 12, pp. 721-765.

[http://www.politicacriminal.cl/Vol_11/n_22/Vol11N22A12.pdf]

errático en Chile y que finalmente termine cayendo en una relativa irrelevancia. Nosotros sabemos, sin embargo, que la premeditación no puede ser interpretada consistentemente como una cualificante individual contingente (asimilable a las otras) y que el único modo correcto de entenderla es bajo el binomio homicidio simple por "afecto" (arrebato o pasión; hoy sería preferible hablar de homicidio explicable en el hecho) vs. homicidio calificado por premeditación. No ver esto ha impedido sacar las conclusiones interpretativas cruciales que pueden extraerse en Chile, a saber: el postulado de que el homicidio simple es, en realidad, un homicidio privilegiado, el que se ve negativamente definido por las circunstancias de calificación distinta de la premeditación. Esta es la única explicación que no sólo toma en cuenta el sentido del concepto de premeditación en su desarrollo por la cultura jurídica europea, sino ante todo los marcos penales presentes (y deformados recientemente) en la codificación chilena.

Lo primero es obvio una vez que uno tiene conciencia del sentido de los conceptos y ya lo hemos revisado exhaustivamente con anterioridad: premeditación es un concepto que sólo se entiende por su negación. Si esto es así, la relación entre el artículo 391 número 1 circunstancia quinta $\mathrm{CP}$ y el artículo 391 número 2 CP sólo puede reproducir la relación que generalmente han tenido asesinato y homicidio simple: el segundo es un homicidio privilegiado por haberse actuado bajo "afecto" (o, en una mejor versión en nuestro desarrollo actual, el homicidio que resulta explicable en el contexto temporal del hecho). Esta interpretación podría ser cuestionada sobre la base del agregado tomado de la legislación española de "premeditación conocida". Se trata, sin embargo, de una pura expresión técnica de la eliminación de ciertas presunciones de calificación presentes en la legislación española anterior a 1848 y que no tiene significación más allá de esto ${ }^{93}$.

Si bien este argumento es difícilmente rebatible, la tesis interpretativa aquí expuesta encuentra su mejor justificación en una consideración de racionalidad en la determinación de las penas. Una observación de los marcos penales del homicidio, al menos antes de la reforma realizada por medio de la Ley 20.779, muestra la adecuación de esta interpretación de un modo que parece hacer difícil criticarla. En efecto, desde el texto original de 1874, los marcos penales del homicidio del CP se dejan describir en base a dos características: (i) el establecimiento de un marco penal relativamente bajo del homicidio simple (la pena mínima del marco legal era presidio mayor en su grado mínimo y sólo llegaba a presidio mayor en su grado medio); y (ii) el establecimiento de un marco penal extraordinariamente amplio del homicidio calificado del artículo 391 número $1 \mathrm{CP}$, el que cubría tres grados: presidio mayor en su grado medio a muerte y, desde la Ley 17.266 de 1970, presidio mayor en su grado medio a presidio perpetuo. ¿Cómo se dejan explicar racionalmente estas dos características?

Una primera respuesta es negando la racionalidad de estos marcos. Esta ha sido una queja constante del medio nacional y que, de hecho, terminó en la dictación de la (catastrófica) Ley 20.779 de 2014. La pena del homicidio simple sería demasiado baja y no sería expresiva del valor supremo del bien jurídico vida, siendo de hecho más baja que la del

\footnotetext{
${ }^{93}$ POLITOFF/GRISOLÍA/BUSTOS, Derecho Penal Chileno. Parte Especial. Delitos contra el individuo en sus condiciones físicas, cit. nota $\mathrm{n}^{\circ}$ 4, p. 133; GARRIDO MONTT, El homicidio y sus figuras penales, cit. nota $\mathrm{n}^{\circ}$ 2, p. 153; ETCHEBERRY, Derecho Penal. Tomo III, cit. nota ${ }^{\circ}$ 3, p. 55.
} 
WILENMANN, Javier. "El sistema de graduación de la pena del homicidio en el derecho chileno".

robo con violencia (presidio mayor en su grado mínimo a presidio mayor en su grado máximo). Ante este hecho y a la observación de la extensión del marco del homicidio calificado, la Ley 20.779 reaccionó con incomprensión: en vez de disminuir la pena del robo, eliminó la parte inferior del marco del homicidio simple y lo aumentó en el caso del homicidio calificado (presidio mayor en su grado máximo a presidio perpetuo). En algo que es especialmente brutal y prácticamente imposible de contrarrestar interpretativamente, la ley en cuestión pretendió continuar además con el modelo impuesto por la Ley Emilia y excluyó la posibilidad de conceder una pena sustitutiva en todo caso de homicidio doloso. Esto es un error evidente para cualquiera que tenga una mínima representación de los casos que se discute deben ser privilegiados: la mujer que mata a su marido que la ha maltratado brutalmente toda su vida y que de hecho la ponía en peligro, pero no alcanza a estar cubierto por el artículo 10 número $11 \mathrm{CP}$, debe ir a la cárcel sin posibilidad de sustitución, del mismo modo en que debe hacerlo quien ve como un familiar sufre de un modo intolerable y se decide a darle muerte para poner fin a ese dolor o quien en un arrebato golpea con demasiada fuerza a un sujeto con el que peleaba.

Todo esto procede de un desconocimiento de la impecable lógica de la graduación de la pena en el delito de homicidio en el CP chileno.

Si el homicidio simple es un homicidio privilegiado - porque no sólo no puede aplicarse ninguna circunstancia especial, sino porque tampoco puede considerarse un hecho premeditado sino que es explicable en la interacción propia del hecho -, entonces es natural que su marco penal sea relativamente benigno y ante todo es natural que pueda proceder sustitución de la pena. La posibilidad de recurrir a atenuantes genéricas sigue haciendo que las penas que pueden aplicar los jueces a verdaderos casos de homicidio simple sean relativamente bajas pese a la dictación de la Ley 20.779, lo que permite contrarrestar esta parte de la reforma sin demasiadas dificultades. El error central se encuentra en su regla de exclusión de las penas sustitutivas: ese error es incontrarrestable para un juez que quiere mantener la sujeción al derecho positivo.

A su vez, si el homicidio calificado incluye casos tan dispares como el homicidio simplemente premeditado y el homicidio premeditado cubierto por otras circunstancias, entonces también es natural que el marco legal sea extraordinariamente amplio, de modo de poder expresar las diferencias de casos particulares, y es normal que se deje a discreción judicial (guiada por criterios dogmáticos de determinación de la pena) la determinación de la procedencia del presidio perpetuo. La doctrina chilena reconocía esto al admitir, de modo completamente mayoritario, la tesis de la calificación alternativa absoluta (o su construcción bajo una denominación aparentemente idiosincrática de "tipo de hipótesis múltiple") del artículo 391 número $1 \mathrm{CP}$, la que en su mejor versión tiene el siguiente sentido: si una calificante resulta aplicable, entonces el resto de las calificantes no puede ser aplicada como agravante genérica que obligue a precisar el marco, pese a que sí pueden servir de criterio de determinación de la pena dentro del marco en aplicación del artículo 69 $\mathrm{CP}^{94}$. El argumento era especialmente convincente cuando la pena máxima del homicidio

\footnotetext{
${ }^{94}$ La tesis en cuestión es defendida por POLITOFF/GRISOLÍA/BUSTOS, Derecho Penal Chileno. Parte Especial. Delitos contra el individuo en sus condiciones físicas, cit. nota ${ }^{\circ} 4$, p. 133; GARRIDO MONTT, El homicidio y sus figuras penales, cit. nota ${ }^{\circ}$ 2, p. 140 y s.; GARRIDO MONTT, Derecho Penal. Tomo III, cit.
} 
Polít. crim. Vol. 11, No 22 (Diciembre 2016), Art. 12, pp. 721-765.

[http://www.politicacriminal.cl/Vol_11/n_22/Vol11N22A12.pdf]

calificado era la pena de muerte ${ }^{95}$, pero su lógica sigue funcionando respecto del presidio perpetuo: si hay obligación de tomar una circunstancia como calificante que gatilla la aplicación del artículo 391 número $1 \mathrm{CP}$ y las demás pueden servir para precisar el marco en aplicación de las reglas sobre agravantes, puede llegarse al punto en que la aplicación de la pena de muerte (hoy: presidio perpetuo) sea formalmente obligatoria sin un momento de valoración individual.

La Ley 20.779 cometió así un doble error al alterar la extensión del marco: aumentó la pena mínima, con lo que aumentó la pena que procede respecto del simple homicidio calificado (como homicidio básico); y redujo la amplitud del margen de expresión de gravedad que suponía el modelo correctamente configurado. Pese a ello, al mantenerse un marco conformado por dos grados, las consecuencias que se siguen para la determinación de la pena son las mismas.

Nada de esto ha cambiado la naturaleza del modelo típico consagrado en el CP chileno, pero sí ha hecho todavía más urgente la estructuración de un sistema consistente de determinación de la pena a este respecto. Con la entrega de pistas relativas a la determinación de la pena pretendemos cerrar esta investigación.

\subsection{La determinación de la pena en supuestos de homicidio calificado.}

Como hemos visto, el modelo chileno de graduación de la pena del homicidio se estructura en base a dos características: (i) la constitución del homicidio simple en tipo privilegiado y del homicidio calificado en tipo básico; y (ii) la generación de un marco penal originalmente benigno en el homicidio simple y un marco penal originalmente amplio en el homicidio calificado.

La Ley 20.799 alteró el punto (ii). En lo relativo al homicidio simple, ésta rompió con la orientación que debe tener el homicidio simple, a saber, establecer penas relativamente bajas a causa de su aplicabilidad a supuestos menos graves. Al reducir el marco legal a un solo grado constituido por el viejo marco superior (presidio mayor en su grado medio), el espacio del juez en la determinación de la pena es ahora especialmente bajo. Pese a ello los jueces siguen pudiendo aplicar atenuantes genéricas. Por aplicación del artículo $67 \mathrm{CP}$, la presencia de una atenuante obliga a aplicar la pena en su mínimum cuando un marco está conformado por una sola pena divisible. Este es el caso en el marco actual. Esto tiene un efecto menor, ya que los jueces tienden en cualquier caso a aplicar la pena inferior posible del marco en la práctica actual. La regla del artículo 67 inciso cuarto CP resulta por ello

nota $^{\circ}$ 3, pp. 52, 64 y s.; MATUS/RAMÍREZ, Lecciones de Derecho Penal Chileno, cit. nota $\mathrm{n}^{\circ}$ 4, p. 61 y s.; ETCHEBERRY, Derecho Penal. Tomo III, cit. nota ${ }^{\circ} 3$, p. 53; Derecho Penal. Tomo II, cit. nota ${ }^{\circ}{ }^{4}$, p. 165; BALMACEDA, Manual de Derecho Penal, cit nota $\mathrm{n}^{\circ}$ 3, p. 38 y s. El argumento que se entrega para defender esta tesis no es, sin embargo, especialmente convincente: se afirma que todas las circunstancias "integran el tipo", aunque sólo una de ellas sirva para gatillar la aplicación de la disposición, por lo que por aplicación del artículo $63 \mathrm{CP}$, ninguna de ellas puede ser luego aplicada como agravante, ya que son inherentes al tipo. El argumento formal no funciona por sí mismo; éste sólo adquiere sentido cuando se lo complementa con la pretensión penológica que subyace al artículo 391 número $1 \mathrm{CP}$.

${ }^{95}$ En este sentido POLITOFF/GRISOLÍA/BUSTOS, Derecho Penal Chileno. Parte Especial. Delitos contra el individuo en sus condiciones físicas, cit. nota $\mathrm{n}^{\circ} 4, \mathrm{p} .115$. 
WILENMANN, Javier. "El sistema de graduación de la pena del homicidio en el derecho chileno".

central: en casos de homicidio explicables por el contexto del hecho (típicamente: pelea) en circunstancias de menor gravedad (ejemplo: provocación, inicio del otro, pudiendo construirse un afecto en el sentido de no premeditación en el homicidio), la aplicación de esta regla permite llegar a penas mucho más adecuadas bajando uno o dos grados del marco legal. La regla que impide la sustitución sigue siendo, sin embargo, un problema de imposible superación.

En lo relativo al homicidio calificado, la alteración introducida por la Ley 20.799 es menor. Si bien era sumamente relevante en un modelo como el chileno la presencia de un marco tan extenso como el que estaba contemplado antes de la dictación de esta ley, la orientación debe seguir siendo la misma. Ella parte de la siguiente constatación: el artículo 391 número $1 \mathrm{CP}$ ya contempla la aplicabilidad del presidio perpetuo calificado, por lo que es una valoración interna al hecho dada por su gravedad (artículo $69 \mathrm{CP}$ ) aquello que determina si esta pena debe o no aplicarse. En algo que la mejor doctrina chilena solía reconocer ${ }^{96}$, ello implica interpretar el artículo 391 número 1 CP como cerrado a la aplicación o al concurso de agravantes, pese a que el concurso pueda ser expresivo de mayor gravedad que justifique la aplicación de la pena mayor. Esto es una consecuencia de la apreciación individual de la adecuación del presidio perpetuo expresada por el BVerfG: el razonamiento formal no es nunca suficiente para justificar la aplicación de una pena tan grave.

Antes de la Ley 20.799, uno podía además señalar que en caso de homicidios simplemente premeditados (en el sentido de homicidio que no pueden ser explicados en la excitación del hecho, pero que no tenían circunstancias ulteriores de mayor agravación), debía aplicarse el mínimum del marco (presidio mayor en su grado medio) y que el presidio mayor en su máximo se encontraba reservado a casos más graves. Pero esto ya no es así. La distinción ahora es más sencilla (y menos adecuada): apreciación individual de merecimiento de aplicación del presidio perpetuo o no. Esto es algo que, a diferencia del sistema alemán, afortunadamente sigue permitiendo el CP chileno.

La última consideración de determinación de la pena ya fue expuesta más arriba: por razones sistemáticas (relación con el artículo 372 bis $\mathrm{CP}$ ), debe interpretarse que el robo

\footnotetext{
${ }^{96}$ Esta interpretación empalma con una discusión española, zanjada por el antiguo artículo 140 del Código Español de 1995, actual artículo 139 número 2 CPE. La discusión versaba sobre una cuestión aparentemente nominal: si el asesinato era un delito autónomo o calificado respecto del homicidio. Un vistazo general a la discusión puede encontrarse en MORALES PRATS, “Art. 138-140”, cit. nota n 30, pp. 58 y ss.; PEÑARANDA RAMOS, Estudios sobre el delito de asesinato, cit. nota $\mathrm{n}^{\circ} 14$, pp. 99 y ss. Si bien los argumentos que se entregaban a favor de la postura de la "autonomía" eran más bien puramente nominales ("tiene identidad propia"), la afirmación de esta naturaleza era utilizada ante todo para justificar la figura del asesinato imprudente y la posibilidad de concursar con el homicidio simple. La tesis tendía a ser rechazada a causa de esta consecuencia, más allá de la debilidad de sus argumentos. Véase BACIGALUPO, Estudios sobre la Parte Especial, cit. nota ${ }^{\circ}$ 5, p. 33 y s. Acertado en la caracterización de la discusión como “confusa", PEÑARANDA RAMOS, Estudios sobre el delito de asesinato, cit. nota ${ }^{\circ} 14$, p. 90ss. A ella también se le vinculaba la afirmación de que era posible el concurso de agravantes, al menos por aplicación del viejo artículo 10 (agravantes genérica) del Código Penal Español anterior a 1995. Así GONZÁLEZ RUS, "El parricidio. El asesinato", p. 64 y s. Esto es un desconocimiento de la relevancia institucional del asesinato: calificar de modo absoluto la procedencia abstracta de la pena de muerte o del presidio perpetuo, para dejar a apreciación individual su adecuación al caso. Esto es precisamente lo que ha distinguido siempre, para bien, al modelo español y chileno respecto del modelo alemán.
} 
Polit. crim. Vol. 11, No 22 (Diciembre 2016), Art. 12, pp. 721-765.

[http://www.politicacriminal.cl/Vol_11/n_22/Vol11N22A12.pdf]

con lesiones gravísimas y el secuestro con lesiones gravísimas o violación no pueden justificar de por sí la aplicación del presidio perpetuo, mientras que el robo con homicidio y secuestro homicidio deben castigarse en principio con presidio perpetuo.

\section{LISTADO BIBLIOGRÁFICO}

ALONSO ÁLAMO, Mercedes, El ensañamiento, Granada: Editorial Comares, 2015.

AMERICAN LAW INSTITUTE, Model Penal Code and Commentaries Part II \$\$ 210.0 to 213.6. Philadelphia: The American Law Institute, 1980.

BACIGALUPO, Enrique, Estudios sobre la Parte Especial del derecho penal, Madrid: Akal, 1991.

BALMACEDA, Gustavo, Manual de Derecho Penal. Parte Especial, Santiago: Librotecnia, 2014.

CARTER, Linda; KREITZBERG, Ellen y HOWE, Scott, Understanding Capital Punishment, $3^{\mathrm{a}}$ ed.; San Francisco: LexisNexis, 2012.

ESER, Albin, Empfielt es sich, die Straftatbestände des Mordes, des Totschlags und der Kindestötung ( $\$ 211$ bis 213, 217 StGB) neu abzugrenzen. Gutachten D für den 53. Deutschen Juristentag. München: Beck, 1980.

ESER, Albin, y STERNBERG-LIEBEN, Detlev, "§ 211" en: ESER, Albin (Ed.), Schönke/Schröder Strafgesetzbuch Kommentar, 29ª ed.; München: C.H. Beck, 2014, pp. 2031-53.

— "Vorbemerkungen zu den $\S \S 211 \mathrm{ff."} \mathrm{en:} \mathrm{ESER,} \mathrm{Albin} \mathrm{(Ed.),} \mathrm{Schönke/Schröder}$ Strafgesetzbuch Kommentar, 29ª ed.; München: C.H. Beck, 2014, pp. 1996-2031

ETCHEBERRY, Alfredo, Derecho Penal. Tomo III. Parte Especial., $3^{\mathrm{a}}$ ed., Santiago: Editorial Jurídica de Chile, 1998.

FEUERBACH, Paul Johann Anselm, Lehrbuch des gemeinen in Deutschland gültigen peinlichen Rechts, Neudruck 1; Aalen: Scientia Verlag (George Friedrich Heyer's Verlag), 1986.

GARRIDO MONTT, Mario, Derecho Penal. Tomo III, $2^{\text {a }}$ ed., Santiago: Editorial Jurídica de Chile, 2002.

- El homicidio y sus figuras penales, Santiago: Ediciones Encina Limitada, 1976.

GONZÁLEZ RUS, J.J., “Artículos 139-140”, en: COBO DEL ROSAL, Manuel (Ed.), Comentarios al Código Penal. Tomo V; Madrid: Edersa, 1999, pp. 121-57.

—, "El parricidio. El asesinato", en: COBO DEL ROSAL, Manuel (Ed.), Manual de Derecho Penal. Parte Especial I; Madrid: Editorial Revista de Derecho Privado, 1993, pp. 45-86.

GRÜNEWALD, Anette, Das vorsätzliche Tötungsdelikt, Tübingen: Mohr Siebeck, 2010. , Reform der Tötungsdelikte, Tübingen: Mohr Siebeck, 2016.

HÄLSCHNER, Hugo, Das gemeine Deutsche Strafrecht. Band II, Nachdruck, Goldbach: Keip Verlag (Adolph Marcus), 1997.

HEINE, Günther, "Stand und Entwicklung der Mordtatbestände", en: KREUZER Arthur et al. (Eds.), Ehrengabe für Anne-Eva Brauneck; Mönchengladbach: Forum Verlag Godesberg, 1999, pp. 315-52.

HEINE, Günther; HÖPFEL, Frank; HUBER, Barbara; JUNG, Heike; 
WILENMANN, Javier. "El sistema de graduación de la pena del homicidio en el derecho chileno".

LAUTENSCHLÄGER, Dunja, LILIE, Hans, et al., "Alternativ-Entwurf Leben (AELeben)", Goltdammer's Archiv für Strafrecht (2008), 193-270.

KADISH, Sanford, SCHULHOFER, Stephen, y STEIKER, Carol, Criminal Law and its Processes, $8^{\mathrm{a}}$ ed., New York: Aspen Publishers, 2007.

KÖHLER, Michael, “Zur Abgrenzung des Mordes”, Goltdammer's Archiv für Strafrecht (1980), 121-42.

KUBICIEL, Michael, "Mord als Grundtatbestand? Ein Vorschlag zur Neukonzeptualisierung der $\S \S 211,212$ StGB”, en: BOCKEMÜHL, Jan et al. (Eds.), Festschrift für Bernd von Heintschel-Heinegg zum 70. Geburtstag; München: Beck, 2015, pp. 267-74.

LABATUT, Gustavo, Derecho Penal. Tomo II, $7^{\mathrm{a}}$ ed., Santiago: Editorial Jurídica de Chile, 1992.

LaFAVE, Wayne, Criminal Law, $5^{\mathrm{a}}$ ed., St. Paul: West Publishing, 2010.

MATUS, Jean Pierre y RAMÍREZ, María Cecilia, Lecciones de Derecho Penal Chileno. Parte Especial, $3^{\mathrm{a}}$ ed., Santiago: Legal Publishing, 2014.

MORALES PRATS, Fermín, “Art. 138-140”, en: QUINTERO OLIVARES, Gonzalo, MORALES PRATS, Fermín (Eds.), Comentarios al Código Penal. Tomo II, $5^{\text {a }}$ ed.; Pamplona: Aranzadi, 2008, pp. 27-63.

MUÑOZ CONDE, Francisco, Derecho Penal. Parte Especial, Valencia: Tirant lo Blanch, 2015.

MÜSSIG, Bernd, "Zur notwendingen Differenzierung von Mord und Totschlag", en: STUCKENBERG, Carl-Friedrich y GÄRDITZ, Klaus Ferdinand (Eds.), Festschrift für Hans-Ulrich Paeffgen zum 70. Geburtstag; Berlin: Duncker \& Humblot, 2015, pp. 301-16.

NEUMANN, Ulfried, “\$ 211”, en: KINDHÄUSER, Urs; NEUMANN, Ulfried y PAEFFGEN, Hans-Ullrich (Eds.), Nomos Kommentar Strafgesetzbuch, $4^{\mathrm{a}}$ ed.; BadenBaden: Nomos, 2013, pp. 1583-1632.

—, "Vor $\S 211 "$, en: KINDHÄUSER, Urs; NEUMANN, Ulfried y PAEFFGEN, Hans-Ullrich (Eds.), Nomos Kommentar Strafgesetzbuch, $4^{\mathrm{a}}$ ed.; Baden-Baden: Nomos, 2013, pp. 1511-83.

PACHECO, Joaquín Francisco, El Código Penal Concordado y Comentado. Tomo III, $2^{\mathrm{a}}$ ed., Madrid: Imprenta de la viuda de Perinat y compañía, 1856.

PALMER, Louis, The Death Penalty in the United States. A Complete Guide to Federal and State Laws, $2^{\mathrm{a}}$ ed., Jefferson, North Carolina: MacFarland \& Company, 2014.

PEÑARANDA RAMOS, Enrique, Estudios sobre el delito de asesinato, Montevideo/Buenos Aires: BdeF, 2014.

PERALTA, José Milton, "Homicidios por odio como delitos de sometimiento", InDret, 4 (2013).

POLITOFF, Sergio, GRISOLÍA, Francisco, y BUSTOS, Juan, Derecho Penal Chileno. Parte Especial, Santiago: Editorial Jurídica de Chile, 2001.

- Derecho Penal Chileno. Parte Especial. Delitos contra el individuo en sus condiciones físicas, $2^{\text {a }}$ ed., Santiago: Editorial Jurídica de Chile, 1993.

QUERALT JIMÉNEZ, Joan J., Derecho Penal Español. Parte Especial, $7^{\mathrm{a}}$ ed., Valencia: Tirant lo Blanch, 2015.

RODRÍGUEZ DEVESA, Jose María, y SERRANO GÓMEZ, Alfonso, Derecho Penal Español, Madrid: Dykinson, 1995. 
Polít. crim. Vol. 11, № 22 (Diciembre 2016), Art. 12, pp. 721-765.

[http://www.politicacriminal.cl/Vol_11/n_22/Vol11N22A12.pdf]

SAFFERLING, Christoph, “§ 211”, en: MATT, Holger y RENZIKOWSKI, Joachim (Eds.), Strafgesetzbuch Kommentar; München: Verlag Franz Vahlen, 2013, pp. 162454.

—, "Vorbemerkung zu den $\S \S 211 \mathrm{ff.",} \mathrm{en:} \mathrm{MATT,} \mathrm{Holger} \mathrm{y} \mathrm{RENZIKOWSKI,}$ Joachim (Eds.), Strafgesetzbuch Kommentar; München: Verlag Franz Vahlen, 2013, pp. 1621-24.

SALIGER, Frank, "Grundfragen einer Reform der Tötungsdelikte", Zeitschrift für die internationale Strafrechtsdogmatik, 2015, 600-604.

SCHAFFSTEIN, Friedrich, Abhandlungen zur Strafrechtsgeschichte, Aalen: Scientia Verlag, 1986.

SCHNEIDER, Hartmut, "§ 211”, en: JOECKS, Wolfgang y MIEBACH, Klaus (Eds.), Münchener Kommentar Strafgesetzbuch Band 4, 2 ed.; München: C.H. Beck, 2012, pp. 467-635.

-, "Vor $\S \S 211 \mathrm{ff.",} \mathrm{en} \mathrm{JOECKS,} \mathrm{Wolfgang} \mathrm{y} \mathrm{MIEBACH,} \mathrm{Klaus} \mathrm{(Eds.),} \mathrm{Münchener}$ Kommentar Strafgesetzbuch Band 4, 2ª ed., München: C.H. Beck, 2012, pp. 360-466.

WESSELS, Johannes, y HETTINGER, Michael, Strafrecht Besonderer Teil 1, 39 ed., (Heidelberg: C.F. Müller, 2015). 
WILENMANN, Javier. "El sistema de graduación de la pena del homicidio en el derecho chileno".

\section{ANEXO I. DISPOSICIONES RELEVANTES SOBRE HOMICIDIO CALIFICADO EN LOS CÓDIGOS HISTÓRICOS CITADOS EN EL CUERPO (TRADUCCIONES PROPIAS):}

\section{Código Penal Francés de 1810:}

"Art. 296: El homicidio cometido con premeditación o alevosía es calificado como asesinato."

"Art.302: Todo culpable de asesinato, parricidio, infanticidio y envenenamiento, será castigado con la pena de muerte (...)."

"Art. 304: El homicidio es castigado con pena de muerte si ha precedido, acompañado o seguido a la perpetración de otro delito.

En todo otro caso, la pena será de trabajos forzados a perpetuidad."

\section{Código Penal Prusiano de 1851:}

$\S 175$. El que mata a otro hombre con premeditación y dolo, comete un asesinato y es castigado con la muerte.

Además de la pena de muerte, se reconocerá la pérdida del honor civil en los casos en que el asesinato es perpetrado sobre un ascendiente sanguíneo o sobre el cónyuge.

$\S 176$. El que mata a otro con dolo, pero sin premeditación, realiza un homicidio y es castigado con trabajos forzosos a perpetuidad."

La versión original del Código Penal para el Imperio Alemán de 1871 tenía, en este aspecto, un contenido casi idéntico en sus $\S \S 211$ y 212. La diferencia más relevante afecta al homicidio simple y no al homicidio calificado: su pena se reduce a trabajos forzosos por no menos de 5 años.

\section{Código Penal Belga de 1867:}

Art. 393. El homicidio (homicide) cometido con la intención de causar la muerte es designado como homicidio simple (meurtre). Se castiga con trabajo forzado a perpetuidad.

Art. 394. El homicidio simple realizado con premeditación es calificado como asesinato. Se castiga con la pena de muerte.

Art. 395. Es calificado como parricidio y será castigado con la pena de muerte el homicidio simple del padre, la madre o de otros ascendientes legítimos, así como el homicidio del padre o la madre natural.

Art. 396. Es calificado como infanticidio el homicidio del niño al momento de su nacimiento o inmediatamente después.

El infanticidio es castigado, según el caso, como homicidio simple o asesinato. 
Polít. crim. Vol. 11, No 22 (Diciembre 2016), Art. 12, pp. 721-765.

[http://www.politicacriminal.cl/Vol_11/n_22/Vol11N22A12.pdf]

Sin embargo, la madre que realiza este delito sobre su hijo ilegítimo será castigada con trabajos forzados de 10 a 15 años. Si la madre comete el delito con premeditación, será castigada con trabajos forzados de 15 a 20 años.

Art. 397. Es calificado como envenenamiento el homicidio simple perpetrado por medio de sustancias que puedan causar la muerte de modo más o menos pronto, cualquiera sea la forma en que hayan sido empleadas o administradas estas sustancias. El envenenamiento se castiga con la muerte.

\section{Código Penal Español de 1848}

Art. 323. El que mate á su padre, madre ó hijo, sean legítimos, ilegítimos ó adoptivos, ó á cualquier otro de sus ascendientes o descendientes legítimos, ó á su cónyuge, será castigado como parricida:

$1^{\circ}$ Con la pena de muerte si concurriese la circunstancia de premeditación conocida, ó la de ensañamiento, aumentando deliberadamente el dolor del ofendido.

$2^{\circ}$ Con la pena de cadena perpétua á la de muerte si no concurriere ninguna de las circunstancias espresadas en el artículo anterior.

Art. 324. El que mate á otro, y no esté comprendido en el artículo anterior, será castigado:

$1^{\circ}$ Con la pena de cadena perpétua á la de muerte, si lo ejecutare con alguna de las circunstancias siguientes:

$1^{a}$ Con alevosía.

$2^{\mathrm{a}}$ Por precio ó promesa remuneratoria.

$3^{\text {a }}$ Por medio de inundación, incendio ó veneno.

$4^{\mathrm{a}}$ Con premeditación conocida.

$5^{\text {a }}$ Con ensañamiento, aumentando deliberada é inhumanamente el dolor del ofendido.

$2^{\circ}$ Con la pena de reclusión temporal en cualquier otro caso.

\section{Código Penal Español de 1870}

Art. 417. El que matare á su padre, madre ó hijo, sean legítimos ó ilegítimos, ó á cualquier otro de sus ascendientes o descendientes, ó á su cónyuge, será castigado, como parricida, con la pena de cadena perpétua á muerte.

Art. 418. Es reo de asesinato el que, sin estar comprendido en el artículo anterior, matare á alguna persona, concurriendo alguna de las siguientes circunstancia.

$1^{\mathrm{a}}$ Con alevosía.

$2^{\mathrm{a}}$ Por precio ó promesa remuneratoria.

$3^{\text {a }}$ Por medio de inundación, incendio ó veneno.

$4^{\mathrm{a}}$ Con premeditación conocida.

$5^{\text {a }}$ Con ensañamiento, aumentando deliberada é inhumanamente el dolor del ofendido.

El reo de asesinato será castigado con la pena de cadena temporal en su grado máximo á muerte. 
WILENMANN, Javier. "El sistema de graduación de la pena del homicidio en el derecho chileno".

Art. 419. Es reo de homicidio el que, sin estar comprendido en el art. 417, matare á otro, no concurriendo alguna de las circunstancias enumeradas en el artículo anterior.

El reo de homicidio será castigado con la pena de reclusión temporal.

\section{ANEXO II: REGLAS RELEVANTES SOBRE HOMICIDIO CALIFICADO EN CÓDIGOS EUROPEOS VIGENTES (TRADUCCIÓN PROPIA)}

\section{Código Penal Francés}

Art. 221-2: El homicidio que precede, acompaña o sigue a otro crimen es castigado con reclusión a perpetuidad.

El homicidio que tiene por objeto preparar o facilitar la comisión de otro delito, o para facilitar la fuga o impunidad del autor o de un cómplice de un delito, es castigo con reclusión a perpetuidad. (...)

Art. 221-3: El homicidio perpetrado con premeditación o alevosía es un asesinato. Éste es castigado con reclusión a perpetuidad. (...)

Art. 221-4: El homicidio es castigado con reclusión a perpetuidad cuando es perpetrado:

$1^{\circ}$ respecto de un menor de quince años;

$2^{\circ}$ respecto de un ascendiente legítimo o natural o sobre el padre o madre adoptivos;

$3^{\circ}$ respecto de una persona cuya particular vulnerabilidad (...) es conocida por el autor o reconocible por éste;

$4^{\circ}-10^{\circ}(\ldots)$.

\section{Código Penal Suizo}

Artículo 112: Asesinato.

En caso de que el autor [de homicidio] actúe con una particular falta de escrúpulos, siendo en particular especialmente reprochables sus motivos, el fin del hecho o la forma de realización, la pena a aplicar será privación perpetua de libertad o privación de libertad no menor a 10 años.

\section{Código Penal Alemán}

\section{$\S 211$ : Asesinato.}

El asesino es castigado con privación perpetua de libertad.

Es asesino el que mata a un ser humano por placer de matar, para satisfacer el deseo sexual, por codicia o por algún otro motivo bajo, de modo alevoso, o con medios generalmente peligrosos o para hacer posible o esconder la realización de otro delito.

\section{Código Penal Austriaco}

$\S 75$. Asesinato: El que mate a otro será castigado con privación de libertad de 10 a 25 años o con privación perpetua de libertad. 
Polít. crim. Vol. 11, No 22 (Diciembre 2016), Art. 12, pp. 721-765.

[http://www.politicacriminal.cl/Vol_11/n_22/Vol11N22A12.pdf]

$\S 76$. Homicidio simple: El que en un estado de excitación severa generalmente perceptible, se deje llevar a matar a otro, será castigado con prisión de 5 a 10 años.

\section{Código Penal Español}

Artículo 139: Será castigado con la pena de prisión de quince a veinticinco años, como reo de asesinato, el que matare a otro concurriendo alguna de las circunstancias siguientes:

$1^{\circ}$ Con alevosía.

$2^{\circ}$ Por precio, recompensa o promesa.

$3^{\circ}$ Con ensañamiento, aumentando deliberada e inhumanamente el dolor del ofendido.

$4^{\circ}$ Para facilitar la comisión de otro delito o para evitar que se descubra.

Cuando en un asesinato concurran más de una de las circunstancias previstas en el apartado anterior, se impondrá la pena en su mitad superior.

Artículo 140: El asesinato será castigado con pena de prisión permanente revisable cuando concurra alguna de las siguientes circunstancias:

1. ${ }^{a}$ Que la víctima sea menor de dieciséis años de edad, o se trate de una persona especialmente vulnerable por razón de su edad, enfermedad o discapacidad.

2. ${ }^{\text {a }}$ Que el hecho fuera subsiguiente a un delito contra la libertad sexual que el autor hubiera cometido sobre la víctima.

3. ${ }^{a}$ Que el delito se hubiera cometido por quien perteneciere a un grupo u organización criminal.

Al reo de asesinato que hubiera sido condenado por la muerte de más de dos personas se le impondrá una pena de prisión permanente revisable. En este caso, será de aplicación lo dispuesto en la letra b) del apartado 1 del artículo 78 bis y en la letra b) del apartado 2 del mismo artículo. 